\title{
Hepatitis B Virus Sensitivity to Interferon-a in Hepatocytes is More Associated with Cellular Interferon Response than with Viral Genotype
}

\footnotetext{
Fang Shen ${ }^{1,2}$, Yaming Li $^{1}{ }^{\natural}$, Yang Wang ${ }^{1}$, Vitina Sozzi ${ }^{3}$, Peter A Revill ${ }^{3}$, Jiangxia Liu ${ }^{1}$, Lu $\mathrm{Gao}^{2}$, Guang Yang ${ }^{2}$, Mengji Lu ${ }^{4}$, Kathrin Sutter ${ }^{4}$, Ulf Dittmer ${ }^{4}$, Jieliang Chen ${ }^{1}$, Zhenghong Yuan $^{1}$
}

${ }^{1}$ Key Laboratory of Medical Molecular Virology, School of Basic Medical Sciences, Shanghai Medical College of Fudan University, Shanghai, China

${ }^{2}$ Roche Innovation Center Shanghai, Shanghai, China

${ }^{3}$ Victorian Infectious Diseases Reference Laboratory, The Royal Melbourne Hospital at the Peter Doherty Institute for Infection and Immunity, Melbourne, Australia

${ }^{4}$ Institute of Virology, University Hospital Essen, University of Duisburg-Essen, Essen, Germany

" These authors contributed equally to this work.

\section{Keywords:}

HBV genotype, Primary human hepatocytes, dHepaRG cells, HepG2-NTCP cells, ISGs

\section{Emails:}

Fang Shen, fang.shen.fs1@roche.com

Yaming Li, 13111010027@fudan.edu.cn

Yang Wang, 596868170@qq.com

Vitina Sozzi, Vitini.Sozzi@vidrl.org.au

Peter A Revill, Peter.Revill@vidrl.org.au

Jiangxia Liu, jxliu@fudan.edu.cn

LuGao,lu.gao@roche.com

Guang Yang, gy1702gy@hotmail.com

Mengji Lu, mengji.lu@uni-due.de

Kathrin Sutter, kathrin.sutter@uni-due.de

Ulf Dittmer, ulf.dittmer@uni-due.de

Jieliang Chen, jieliangchen@fudan.edu.cn

Zhenghong Yuan, zhyuan@shmu.edu.cn

This is the author manuscript accepted for publication and has undergone full peer review but has not been through the copyediting, typesetting, pagination and proofreading process, which may lead to differences between this version and the Version of record. Please cite this article as doi:10.1002/ hep.29609. 


\section{Correspondence:}

Zhenghong Yuan, PhD, MD (zhyuan@shmu.edu.cn)

Jieliang Chen, PhD, MB (jieliangchen@fudan.edu.cn)

Add: Rm 1115, Zhidao Bldg, 138 YiXueYuan Rd, Shanghai 200032, China

Tel: $+86-21-54237669$

Fax: +86-21-64227201

\section{Abbreviations:}

HBV, hepatitis B virus; cccDNA, covalently closed circular DNA; pgRNA, pre-genomic RNA; PHH, primary human hepatocyte; dHepaRG, differentiated HepaRG; HBeAg, HBV e antigen; HBsAg, HBV surface antigen; STAT1, signal transducer and activator of transcription 1; STAT2, signal transducer and activator of transcription 2; ISG, interferonstimulated genes; A3G, APOBEC $3 \mathrm{G}$; $\mathrm{IC}_{50}$, the half maximal inhibitory concentration.

\section{Financial support statement:}

This work was supported by the grants from the National Natural Science Foundation of China (81461130019 and 91542207), German Research Foundation (SFB/Transregio TRR60) and the Innovation Program of Shanghai Municipal Education Commission (201701-07-00-07-E00057).

\section{Conflict of interest statement:}

Yaming Li, Yang Wang, Vitina Sozzi, Jiangxia Liu, Mengji Lu, Kathrin Sutter, Ulf Dittmer, Jieliang Chen and Zhenghong Yuan declared that they do not have anything to disclose regarding funding or conflict of interest with respect to this manuscript. Fang Shen and $\mathrm{Lu}$ Gao are employees of Roche Innovation Center Shanghai, Guang Yang is ex-employee of Roche Innovation Center Shanghai and Peter Revill received grants from Gilead Sciences.

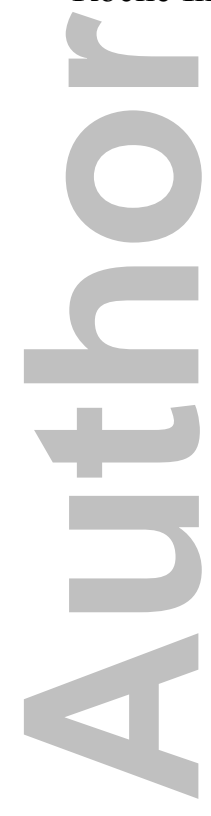




\begin{abstract}
Interferon- $\alpha$ (IFN- $\alpha)$ is used to treat chronic HBV infection but only $20-40 \%$ of patients respond well. Clinical observations have suggested that HBV genotype is associated with the response to IFN therapy, however, its role in viral responsiveness to IFN in HBV-infected hepatocytes remain unclear. Here, we produced infectious virions of HBV genotypes A to D to infect three well-recognized cell culture-based HBV infection systems including primary human hepatocytes (PHH), differentiated HepaRG (dHepaRG) and HepG2-NTCP cells to quantitatively compare the antiviral effect of IFN- $\alpha$ on HBV across genotypes and cell models. The efficacy of IFN- $\alpha$ against HBV in hepatocyte was generally similar across genotype A2, B5, C2 and D3, however, was significantly different among the infection models as the $\mathrm{IC}_{50}$ value of IFN- $\alpha$ for inhibition of viral DNA replication in $\mathrm{PHH}(<20 \mathrm{U} / \mathrm{ml})$ and dHepaRG cells were much lower than that in HepG2-NTCP cells $(>500 \mathrm{U} / \mathrm{ml})$. Notably, even in PHH, IFN- $\alpha$ did not reduce HBV cccDNA at the concentrations for which viral antigens and DNA replication intermediates were strongly reduced. The three cell culture models exhibited differential cellular response to IFN- $\alpha$. The genes reported to be associated with responsiveness to IFN- $\alpha$ in patients were robustly induced in PHH while weakly induced in HepG2-NTCP cells upon IFN- $\alpha$ treatment. Reduction or promotion of IFN response in PHH or HepG2-NTCP cells significantly attenuated or improved the inhibitory capacity of IFN- $\alpha$ on HBV replication, respectively._Conclusion: In the cell culture-based HBV infection models, the sensitivity of HBV to IFN- $\alpha$ in hepatocytes is determined more by the cellintrinsic interferon response than by viral genotype, and improvement of the IFN response in HepG2-NTCP cells promotes the efficacy of IFN- $\alpha$ against HBV.
\end{abstract}


Hepatitis B virus (HBV) is a hepatotropic partially double-stranded DNA virus. Despite the availability of effective vaccines, chronic HBV infection (CHB), affecting approximately 240 million people worldwide, remains a health burden and is the main risk factor for the development of liver cirrhosis and hepatocellular carcinoma. Based on $8 \%$ sequence divergence of the entire $3.2-\mathrm{kb}$ genome, HBV isolates worldwide can be grouped into at least 9 genotypes (A-I) and numerous sub-genotypes, of which the geographic distributions are quite distinct. The major genotypes worldwide are A to D. Genotypes A and D are the two most prevalent genotypes in Europe, whereas genotypes $\mathrm{B}$ and $\mathrm{C}$ are the two dominant genotypes prevalent in eastern Asia and Oceania (1).

Interferon alpha (IFN- $\alpha$ ) was initially discovered sixty years ago because of its ability to interfere with viral replication and has been demonstrated to induce multiple interferonstimulated genes (ISGs) to inhibit HBV replication by affecting multiple steps of the viral life cycle in HBV-infected hepatocytes. It also has immunomodulatory activities that modulate the immune responses to HBV infection $(2,3)$. By binding to the IFN- $\alpha$ receptor 1 (IFNAR1) and IFNAR 2 on the cell surface, IFN- $\alpha$ leads to the activation of Janus kinase 1 (JAK1) and tyrosine kinase 2 (TYK2), which in turn phosphorylate a single tyrosine residue of signal transducer and activator of transcription (STAT) 1 and STAT2. The activated STAT1 and STAT2 heterodimerize with interferon regulatory factor 9 (IRF9) to form the ISGF3 transcription factor complexes and then translocate into the nucleus to initiate transcription of ISGs (4). Administration of IFN- $\alpha$ and its pegylated form (PEG-IFN- $\alpha$ ) to patients chronically infected with HBV has been widely used in the clinic, however, only $20-40 \%$ of patients have $\mathrm{HBeAg}$-seroconversion after 48 weeks of treatment $(5,6)$.

Both viral and host factors have been implicated in affecting the responsiveness to IFN$\alpha$ therapy. Evidence from the clinic suggests factors including female gender, higher baseline alanine aminotransferase (ALT) levels and low baseline HBV DNA are associated with the prognostic parameters for sustained response following the IFN therapy (7). Moreover, HBV genotype A and B was found to be associated with better response to IFN treatment in CHB patients compared with genotype $\mathrm{D}$ and $\mathrm{C}$, respectively $(8,9)$. This has been supported by studies using transient transfection-based cell and mouse models (10), however, the intrinsic weakness of the these models that do not allow study of the complete viral life-cycle make it difficult to reach solid conclusions. As the major target of HBV infection, hepatocytes are equipped with relatively intact pattern recognition receptors (PRRs) and IFN system and can initiate robust innate immune responses (11-13). It has been shown that hepatocytes alone can induce HBV antigen decline during IFN- $\alpha$ administration, in the absence of an adaptive immune response (14). In turn, HepaRG hepatocytes transduced with baculovirus expressing the HBV genome can mount an innate response, followed by an IFN-driven control of HBV replicative intermediates (15). However, the role of HBV genotype in determining the response of HBV to IFN therapy in HBV-infected hepatocytes remain to be investigated.

Here, we produced infectious virions of HBV genotypes A to D to infect three wellcharacterized cell culture-based models $(16,17)$ including primary human hepatocytes $(\mathrm{PHH})$, differentiated HepaRG (dHepaRG) and HepG2-NTCP cells to quantitatively compare the antiviral effect of IFN- $\alpha$ on HBV across different genotypes in human hepatocytes. The results showed that while the inhibitory capacity of IFN- $\alpha$ on HBV replication in HBVinfected cells was generally similar among the four genotypes, it was strikingly different among the three cell culture-based HBV infection models. Differential levels of IFN- $\alpha-$ induced JAK-STAT activation and patterns of ISGs induction were observed in distinct cell models, while reduction or promotion of the IFN responses in PHH or HepG2-NTCP cells significantly attenuated or improved the inhibitory capacity of IFN- $\alpha$ on HBV replication, 
respectively. Our findings indicate that in the absence of an adaptive immune response, the cellular interferon response plays a more dominant role in determining the responsiveness of HBV to IFN- $\alpha$ in hepatocytes than viral genotype per se.

\section{Materials and methods}

\section{Cells, antibodies and reagents}

HepG2, HepG2-NTCP (kindly provided by Yi Ni and Stephan Urban), dHepaRG and PHH (Bioreclamation IVT) were cultured as described previously (18). Antibodies used here are listed in Supplementary Table 2. The primers used for qPCR were synthesized by Biosune and the primer sequences are listed in Supplementary Table 3. IFN- $\alpha$ (2a) (PBL Assay Science), PEG-IFN- $\alpha-2$ a (Pegasys, Roche), Cycloheximide (CHX, Sigma) and Tofacitinib (Selleck) were purchased from the indicated manufacturers. Recombinant human IFN- $\alpha 2$ and IFN- $\alpha 14$ were produced as we previously described (19).

\section{Plasmids, virus production, in vitro viral infection}

The 1.3 mer HBV DNA constructs for genotypes A2, B5 (formerly named as B6), and D3 were prepared by Genscript USA, as we previously described (20). pHBV C2 (3.8) was described in supplementary methods. HBV virions of different genotype were obtained from the culture supernatant of HepG2 cells transfected with the corresponding expression plasmid. HBV genotype D was derived from the culture supernatant of HepAD38 cells. HBV DNA concentrations of these viruses were quantified by qPCR. HBV infection was performed with same viral genome equivalents (vge)/cell in the presence of 4\% PEG 8000 (For more details see supplementary methods).

\section{Detection of HBsAg, HBeAg, HBV DNA and cell viability}

$\mathrm{HBV}$ surface antigen (HBsAg) and $\mathrm{HBV}$ e antigen ( $\mathrm{HBeAg}$ ) levels in the cell culture supernatant were measured using CLIA ELISA (Autobio). HBV DNA levels in culture medium or purified HBV particles were extracted by MagNA Pure 96 system (Roche), and then quantified by real-time PCR with universal primers and probe for HBV genome amplification across genotype A to D. The viral genome equivalent copies were calculated based on a standard curve generated with known copy numbers. Cell viability was determined using the Cell Counting Kit-8 (CCK-8) (Dojindo).

\section{Hirt DNA extraction and detection of HBV cccDNA}

HBV cccDNA was extracted from HBV infected cells by a modified Hirt method as previously described $(21,22)$. The HBV cccDNA in extracted Hirt DNA was either quantified by qPCR with specific primers or detected by Southern blot analysis (For details see supplementary methods)

Reverse transcription, real-time PCR analysis, immunofluorescence assay and Western blot analysis

Described in the supplementary methods.

\section{Statistical analysis}

$\mathrm{IC}_{50}$ values were calculated using GraphPad Prism version 6 (GraphPad Software Inc., US). Significant differences were analyzed using a two-tailed unpaired t-test, or two-way ANOVA followed by Bonferroni's test to determine the differences in multiple comparisons. P-values were calculated, and statistical significance is reported as $*(p<0.05), * *(p<0.01)$. Data are presented as the mean \pm standard deviation. 


\section{Results}

HBV genotype A2/B5/C2/D3 virions produced from cell culture replicated efficiently in hepatocyte cell culture systems

To examine the role of viral genotypes in affecting the sensitivity of HBV to IFN- $\alpha$ in the context of viral infection, we firstly obtained HBV virions of genotypes A to D with transient transfection methods (Fig S1). The infectivity of HBV genotype viruses from cell culture were tested in PHH. Viruses of HBV genotype A2, B5, C2 and D3 showed good replication in PHH, and thus they were used for further studies. At the same time, genotype D derived from the HepAD38 cells was included as control.

In $\mathrm{PHH}$, the kinetics of secreted $\mathrm{HBsAg}, \mathrm{HBeAg}$ and HBV DNA post infection were measured (Fig 1A) and the HBs expression in infected cells was examined by immunostaining (Fig 1B). HBV DNA levels in medium decreased at early time points analyzed post infection, likely reflecting carry-over DNA in the inoculum that was subsequently removed by washing and changing the medium. Secreted $\mathrm{HBsAg}, \mathrm{HBeAg}$ and DNA levels of HBV genotype A2, B5, C2 and D3 at the end point in three hepatocyte cell infection systems are summarized in supplementary Table 1. As dHepaRG and HepG2-NTCP cells are also well-established infection cell systems for HBV, we further confirmed the infectivity and viral replication levels of the viruses using dHepaRG and HepG2-NTCP cells (Fig S2). The overall viral replication levels of four genotypes were best in PHH, while were lower in dHepaRG and HepG2-NTCP cells, particularly in HepG2-NTCP cells using transiently transfected derived virus, for reasons that are currently under investigation. Productive infection was only established in HepG2-NTCP cells using AD38-derived HBV genotype D. The levels of cccDNA in PHH were measured and examined by southern blot analysis (Fig 1C), which showed that cccDNA of A2, B5, C2 and D3 could be detected in infected PHH. The weak band of C2 may be due to lower HBV DNA level compared to other genotypes. cccDNA of each genotype was confirmed by heat denaturation and further EcoRI digestion. As B5 has a T base change while others are $\mathrm{G}$ in the EcoRI recognition site, B5 exhibited resistant to EcoRI digestion. Taken together, HBV virions of genotypes A2, B5, C2 and D3 were successfully produced, and although there were some differences in the productions of viral DNA and antigens among the four genotypes, they all established infection and replicated in PHH and dHepaRG cells.

\section{Difference in the overall anti-HBV effect of IFN- $\alpha$ among genotype A2/B5/C2/D3 in} PHH was not marked

Many clinical studies have reported that different HBV genotypes show different response rate to IFN- $\alpha$ treatment. Since, multiple factors including HBV genotypes and individual differences of patients may contribute to treatment response in clinical studies, studies on the role of $\mathrm{HBV}$ genotype in response to IFN- $\alpha$ using more simplified in vitro infection systems are required. Therefore, based on the established effective infection of HBV genotype A2, B5, C2 and D3 in PHH, we further investigated the sensitivity of $\mathrm{HBV}$ in response to IFN- $\alpha$ in PHH. Anti-HBV activities of IFN- $\alpha$ on different HBV genotypes were assessed either with treatment before viral infection or post infection (Fig 2A). PHH were infected with genotype A2, B5, C2 and D3 at the same viral genome equivalents (1000 vge) respectively, and genotype D (derived from HepAD38 cells) was included at a lower ( $250 \mathrm{vge}$ ) viral genome equivalents to obtain similar viral replication 
levels. Although replication phenotype showed differences among the four HBV genotypes studied, IFN- $\alpha$ significantly reduced expression of $\mathrm{HBsAg}$ and $\mathrm{HBeAg}$ in all of them with treatment from day 3 to day 12 post infection in a dose dependent manner (Fig 2B). A marked inhibition ( $90 \%$ or greater) on secreted HBV DNA of four genotypes was observed even at the lowest dose $(20 \mathrm{U} / \mathrm{ml})$, which indicates that IFN- $\alpha$ treatment led to a stronger and faster HBV DNA decline than HBsAg and HBeAg decline in HBV-infected PHH with 9 days of treatment. Pre-incubation with IFN- $\alpha$ for 24 hours before viral infection of different genotype viruses also showed significantly reduction of secreted $\mathrm{HBsAg}$ and $\mathrm{HBeAg}$ in a dose-dependent manner and they were similar across distinct genotypes (Fig 2D). IFN- $\alpha$ treatment with three doses (500, 100 and $20 \mathrm{U} / \mathrm{ml}$ ) did not lead to detectable hepatotoxicity (Fig 2C and Fig S4A). Considering the high donor-todonor variability of $\mathrm{PHH}$, we confirmed the effect of IFN- $\alpha$ on HBV across genotypes in PHH derived from another donor, and obtained similar results (Fig S3). The susceptibility of each HBV genotype to IFN- $\alpha$ was further evaluated by determining $\mathrm{IC}_{50}$ values of IFN- $\alpha$ based on the measurement of secreted HBsAg, HBeAg and HBV DNA (Table 1). Although statistically differences of HBsAg reduction in genotype A2 $(\mathrm{P}<0.05)$, of HBV DNA reduction in genotype $\mathrm{B} 5(\mathrm{P}<0.01)$ and of $\mathrm{HBsAg} / \mathrm{HBeAg}$ reduction in genotype $\mathrm{D}$ $(\mathrm{P}<0.01)$ were observed, differences in the overall inhibitory effect of IFN- $\alpha$ on HBV replication across genotypes in PHH was not marked. Notably, higher amount of HBV virions inoculated was found to be associated with less effectiveness of IFN- $\alpha$ (Fig 2E), which may explain the small differences observed in A2 and D in our system and is similar to the clinical observations that patients with higher viral load have lower responsiveness to IFN- $\alpha$.

Next, the effects of IFN- $\alpha$ on cccDNA abundance in cells infected with HBV of different genotypes was examined. Unlike the previous report showing that IFN- $\alpha$ reduced HBV cccDNA in PHH and dHepaRG cells (23), we did not observe reduction of HBV cccDNA under IFN- $\alpha$ treatment at the concentrations for which viral antigen expression and viral DNA replication intermediates were dramatically reduced in $\mathrm{PHH}$ (Fig 3A). Considering that the PEG-IFN- $\alpha$ is currently more widely used in clinic and has been shown to lead to better sustained responses in patients, we further examined the antiHBV effect of PEG-IFN- $\alpha$ in vitro. Similar to that of IFN- $\alpha$, while PEG-IFN- $\alpha$ treatment significantly inhibited HBV (genotype D) replication level, it showed weak effect on reducing cccDNA level even in the dose of $360 \mathrm{ng} / \mathrm{ml}$ (Fig 3B). Together, these results suggested that IFN- $\alpha$ did not much affect the level of cccDNA at the concentrations for which HBV DNA replication and HBV antigens expression were strongly reduced in PHH.

\section{Anti-HBV activity of IFN- $\alpha$ showed a striking difference among distinct cell culture systems}

To evaluate the host factors related to efficacy of IFN- $\alpha$ against HBV in hepatocytes, antiviral activity of IFN- $\alpha$ against four HBV genotypes were further examined in other hepatocyte cell culture systems. dHepaRG cells were infected with HBV genotype A2, B5, C2, D3 and D, and further treated with IFN- $\alpha$ (500, 100 and $20 \mathrm{U} / \mathrm{ml})$ for 9 days after viral infection (Fig 4A). Consistent with the results obtained in $\mathrm{PHH}$, dose-dependent decline in $\mathrm{HBsAg}$ and $\mathrm{HBeAg}$ levels were observed and similar across the four genotypes (Fig 4B), however, the reduction of viral DNA in response to IFN- $\alpha$ varied across HBV genotypes. The HBV DNA level in the cell supernatant was found to be higher in genotype $\mathrm{B} 5$ and genotype $\mathrm{D}$ than that in genotype $\mathrm{A} 2$ and $\mathrm{C} 2(\mathrm{P}<0.01)$ in dHepaRG cells. 
Considering there was significant reduction of pgRNA in genotype D (data not shown), there may have been viral inoculum or inactive DNA attached to the cells. Quite different from PHH and dHepaRG cells, HepG2-NTCP cells were observed with poor anti-HBV effect in response to IFN- $\alpha$ on HBV genotype D (Fig 4C), and limited reduction was only observed with $500 \mathrm{U} / \mathrm{ml}$ of IFN- $\alpha$. Although the replication levels of HBV genotypes $\mathrm{A} 2 / \mathrm{B} 5 / \mathrm{C} 2 / \mathrm{D} 3$ in HepG2-NTCP cells were low for reasons that are under investigation, similar poor anti-HBV effects of IFN- $\alpha$ were observed (Fig S5 and Fig S4B). The calculated $\mathrm{IC}_{50}$ values are summarized in Table 1 , and statistical analysis of the responsiveness to IFN- $\alpha$ among $\mathrm{HBV}$ genotypes were determined with multiple comparison. Overall, these results suggested that while HBV genotypes showed minor influence on the anti-HBV effect of IFN- $\alpha$, the IFN- $\alpha$ mediated inhibition of HBV replication and antigens production showed strikingly difference among distinct cell models.

Differential activation of IFN- $\alpha$ signaling and ISG induction was observed in PHH, dHepaRG and HepaG2-NTCP cells

Since the efficacy of IFN- $\alpha$ for inhibition of HBV replication significantly varied among the three infection cell culture models, and it remains controversial whether the HepG2 cells (from which HepG2-NTCP was generated) is defective in IFN- $\alpha$ signaling $(24,25)$, we further compared the interferon responses among the three cell models to understand the difference in anti-HBV activity. The IFN- $\alpha$-induced phosphorylation of STAT1 and STAT2 was clearly detected in all three types of cells in a dose-dependent manner with similar levels following normalization to the baseline expression of STAT1 and STAT2 (Fig 5A). However, the three cell models were distinct in the expression pattern of ISGs. Particularly, while the induction of primary response ISGs, such as OAS1, IFITM2, STAT1 and IRF9, in HepG2-NTCP cells was comparable to that in PHH and dHepaRG, ISGs including CXCL10, GBP5, GBP1 and WARS, which have been previously reported to be associated with the IFN- $\alpha$ responses in patients $(26,27)$, were either absent or weakly expressed in HepG2-NTCP cells. The expression levels of APOBEC3G, ISG20 and APOBEC3A, which have been shown to have anti-HBV activities, were also lower in HepG2-NTCP cells than that in PHH and dHepaRG cells (Fig 5B, 5C and Fig S6). Considering that the actions of IFN- $\alpha$ are closely associated with the cell surface receptor concentrations and a much higher number of IFNAR receptors is associated with anti-proliferative rather than antiviral activity $(28,29)$, we further examined the expression of IFNAR1, IFNAR2, TYK2 and JAK1. The results showed that these signaling molecules expressed highly in HepG2-NTCP, but at a much lower level in PHH (Fig 5D), which might contribute to the differential induction pattern of ISGs and antiviral effects. Furthermore, we showed that the induction of APOBEC3G and ISG20 was abolished in $\mathrm{PHH}$ in the presence of cycloheximide (CHX), a eukaryote protein synthesis inhibitor (Fig 5E), which suggested that the induction of a subset of genes that depends on primary protein synthesis is intact in $\mathrm{PHH}$ but is partially incompetent in HepG2-NTCP cells and this might be associated with the poor anti-HBV effect of IFN- $\alpha$ in HepG2-NTCP cells.

Reduction or promotion of the cellular interferon response attenuated or improved the anti-HBV efficacy of IFN- $\alpha$ in hepatocytes, respectively 
To confirm that the differential cellular interferon responses are associated with the efficacy of IFN- $\alpha$ against HBV, we further examined whether the inhibitory capacity of IFN- $\alpha$ on HBV replication could be manipulated by reduction or promotion of cellular IFN responses. By using a JAK inhibitor (Tofacitinib), IFN- $\alpha$-activated STAT1 and STAT2 phosphorylation and ISGs induction were intensively inhibited in PHH (Fig 6A) and, as expected, the IFN- $\alpha$-mediated inhibition of HBV replication and induction levels of ISGs were significantly decreased (Fig 6B). Moreover, treatment of HepG2-NTCP cells with IFN- $\alpha 14$, one of the human IFN- $\alpha$ subtypes with the highest binding affinity to IFNAR1 and IFNAR2 (30) and the most potency in anti-HIV actions $(19,31)$, induced higher expression of IFITM1 and significant expression of ISG20, GBP5 and TNFSF13B (Fig 6C), which were absent or weakly induced upon treatment of the commonly-used IFN- $\alpha$ (IFN- $\alpha 2$ ). More interestingly, along with the induction of ISGs, significant reduction of the HBV DNA and HBeAg was observed in HepG2-NTCP cells and the $\mathrm{IC}_{50}$ value of IFN- $\alpha 14$ for HBV inhibition was 10-100 fold lower than that of IFN- $\alpha$ (Fig 6D). Taken together, these results suggested that the intrinsic cellular response of host hepatocyte to IFN- $\alpha$ is closely associated with the inhibitory capacity of IFN- $\alpha$ on HBV replication, and promotion of the IFN response in HepG2-NTCP cells by strong stimulation could significantly improve the efficacy of IFN- $\alpha$ against HBV.

\section{Discussion}

To apply more effective personalized medicine and optimal cost-effectiveness, a number of prognostic parameters for prediction of the sustained response following IFN treatment have been developed $(7,32)$. However, therapeutic regimens based on these parameters have not shown a much improved response rate to IFN treatment. One of the reasons behind the low-confidence prediction is lack of experimental data which comprehensively characterizes host and viral factors involving the effectiveness of IFN- $\alpha$ against HBV. With the development of the cell culture-based HBV infection models $(16,17)$, we now have better tools to examine the sensitivity of HBV to IFN- $\alpha$ at the cellular and molecular levels.

This study focused on the role of HBV genotypes in affecting the effectiveness of IFN- $\alpha$ in hepatocytes, which, in clinic, has been shown to be an important factor associating with the outcome of IFN treatment. The inhibitory capacity of IFN- $\alpha$ on HBV replication in HBVinfected cells was found to be generally similar among genotype A2, B5, C2 and D3, however, was strikingly different among three cell culture-based HBV infection models. Moreover, different cell models exhibited differential responses to IFN- $\alpha$ and suppression or promotion of the cellular IFN response significantly attenuated or improved the inhibitory capacity of IFN- $\alpha$ on HBV replication, respectively. These results indicate that, compared to the viral genotypes, the host response to IFN- $\alpha$ may play a more dominant role in affecting the responsiveness of HBV to IFN- $\alpha$ in hepatocytes. Considering that the antiviral effects of IFN- $\alpha$ on human hepatocytes, without immune cell responses, was reported to be sufficient to induce sustained responsiveness and trigger substantial HBV antigen decline (14), our study provides new insights into the mechanism of the resistance of HBV to IFN- $\alpha$ therapy by showing the potential importance of the cellular IFN- $\alpha$ responsiveness, rather than the viral genotypes, in determining the outcome of IFN- $\alpha$-based treatment of HBV infection.

Evidence from clinics have suggested an association between the effectiveness of IFN- $\alpha$ therapy for treatment of HBV infection and the HBV genotype. Therapy is most effective for patients infected with HBV genotype A2 (compared with genotype D) (8) and least effective for patients infected with HBV genotype C (compared with genotype B), irrespective of 
whether the IFN used was conventional or pegylated. The reasons for these differences remain unknown, but notably, differences in IFN response of HBV genotype A2 and the genotypes $\mathrm{B}$ and $\mathrm{C}$ may relate to the fact that genotype $\mathrm{A} 2$ is mostly adult acquired whereas genotypes $\mathrm{B}$ and $\mathrm{C}$ are transmitted at birth or in very early childhood in a large proportion of Asian patients. The differential IFN response observed among these patients might be partially a reflection of the transmission-related immune-tolerance or the host genetic polymorphisms, rather than the viral genotypes. Nonetheless, genotype D is often adult acquired, yet patients infected with this genotype respond poorest to IFN treatment. Although our results here showed that the sensitivity of HBV to IFN- $\alpha$ in human hepatocyte culture systems is similar across distinct genotypes, considering that the immune modulating function of IFN- $\alpha$ may also play important role in induction of favorable treatment response (33), the role of HBV genotype in IFN- $\alpha$ therapeutic efficacy in clinic cannot be ruled out.

Another possibility is that although we did not observe significant differences in the responsiveness of HBV genotypes to IFN- $\alpha$ in hepatocytes, the modulating activity of the viral $\mathrm{HBs}$ and $\mathrm{HBe}$ antigens on the functions of immune cells $(34,35)$ and the propensity to develop mutations previously associated with impaired IFN responses, such as the basal core promoter (BCP) mutations (36), may differ among HBV genotypes, which will lead to the variation in HBV replication, antigens production and secretion $(20,37)$. Our studies were restricted to wild-type $\mathrm{HBV}$, for a limited time period. Here, different levels of $\mathrm{HBV}$ replication and antigen expression among HBV genotypes in HBV-infected cells with the same viral genome equivalent per cell were observed. Since it is difficult to investigate immune modulatory effects using current in vitro systems, new models are required to investigate associations between virological differences across genotypes and the genotyperelated differences in responsiveness to IFN- $\alpha$. In addition, in clinic, genotype-specific sensitivity might first become apparent only following long-term treatment, e.g. due to differential propensity to acquire mutations that may mediate resistance; again this is challenging to address in HBV cell culture systems with limited culture duration. Similarly for $\mathrm{HCV}$, where genotype is strongly associated with differential response rates in the clinic, it has been difficult to identify genetic correlates of differential sensitivity to interferon in vitro $(38,39)$. This may be due to interferon acting on various cell factors and not by a single well defined mechanism, enabling the virus to escape using different mechanisms. Further, it should be noted that in general only one isolate per genotype was included in our study, which is likely not entirely representative. In addition, due to the poor infectivity of B1 and B2 clones in our system, B5 was used here as a representative clone of genotype B, however, this subtype is not an Asian genotype but actually localized to Alaska/South America.

Compared to the subtle differences in IFN sensitivity observed among genotypes, it was clear that higher HBV replication levels lead to lower sensitivity of HBV to IFN- $\alpha$ (Fig 2E). We believe this reflects the clinical observation that higher viral load is associated with poor responsiveness to IFN- $\alpha$, which might be the result of stronger antagonism of IFN- $\alpha$ activity $(34,40,41)$ as well as the dispersed distribution of ISGs. It has been reported that IFN- $\alpha-$ mediated control of HBV infection involves epigenetic suppression of cccDNA transcription and inhibition of viral replication (42-44). In addition, a recent report showed that high-dose IFN- $\alpha$ noncytopathically reduced cccDNA levels in PHH and dHepaRG cells (23). Unlike this report, in our system IFN- $\alpha$ did not significantly reduce HBV cccDNA at the concentrations for which the markers of viral transcription and replication were strongly reduced, which supports the notion that the major effect of IFN- $\alpha$ against HBV is the suppression of viral transcription and replication $(14,43-45)$ and only very-high-dose IFN- $\alpha$ may reduce the cccDNA (23). Further studies are required, though technically difficult, to determine the physiological efficiency of IFN- $\alpha$-mediated cccDNA loss in the context of 
IFN-based HBV therapies, and whether such loss of cccDNA is completely noncytopathic or is relative to IFN- $\alpha$-induced cell death, proliferation or immunomodulatory effect should be carefully evaluated. Notably, as a DNA virus, HBV is theoretically less responsive than RNA viruses, such as $\operatorname{HCV}(27,46)$, and the mechanisms responsible for IFN- $\alpha$ treatment responses are different in $\operatorname{HBV}$ and $\operatorname{HCV}(27,42,47)$. Moreover, HBV was shown to lack an interferon sensitivity-determining region (48). Thus, more precise definition of the mechanisms by which IFN- $\alpha$ inhibits HBV replication will further clarify the factors involved in $\mathrm{HBV}$ resistance to IFN- $\alpha$.

Since significant differences in the $\mathrm{IC}_{50}$ value of IFN- $\alpha$ for inhibition of $\mathrm{HBV}$ replication were observed among the infection models as PHH $<$ dHepaRG $<$ HepG2-NTCP, we further compared the response of host cells themselves to IFN- $\alpha$ among the three cell models. We found that the expression of ISGs were partially incompetent in HepG2-NTCP cells. In particular, a set of ISGs identified to be related to the IFN responses by transcriptome analysis in liver biopsies of CHB patients $(26,27)$, including CXCL10, GBP5, TNFSF13B and WARS, were robustly induced by IFN- $\alpha$ in PHH and dHepaRG cells but hardly or only slightly induced in HepG2-NTCP cells. Previous reports suggested that while the HepG2derived cells could mount antiviral interferon responses $(15,49)$ and have the positive feedback mechanisms in the IFN signaling (25), they might lack secondary pathways which is responsible for the induction of secondary IFN response genes (24). Our data supports the notion that the primary IFN signaling activation and ISG induction are intact but not translate into anti-HBV effect (15) in HepG2-NTCP cells, while the induction of a certain subset of ISGs is impaired or deficient in the cells. Moreover, we showed that the impaired ISGs induction in HepG2-NTCP cells could be restored or enhanced by using IFN- $\alpha 14$ and this was accompanied by the reduction of HBV replication, suggesting that the magnitude of cellular IFN responses may play an important role in IFN treatment response. It will be interesting to further characterize the key molecule(s) and pathway(s) responsible for antiHBV effect of IFN- $\alpha 14$ and to investigate the contribution of the induction of certain subset of ISGs to IFN-mediated inhibition of HBV replication. Altogether, these results deepen our understanding of the mode of anti-HBV actions of IFN- $\alpha$ and facilitate the identification of novel markers of the host responsiveness to IFN- $\alpha$ in patients. 


\section{References}

1. Tong S, Revill P. Overview of hepatitis B viral replication and genetic variability. J Hepatol 2016;64:S4-16.

2. Revill P, Yuan Z. New insights into how HBV manipulates the innate immune response to establish acute and persistent infection. Antivir Ther 2013;18:1-15.

3. Xia Y, Protzer U. Control of Hepatitis B Virus by Cytokines. Viruses 2017;9.

4. Ivashkiv LB, Donlin LT. Regulation of type I interferon responses. Nat Rev Immunol 2014;14:36-49.

5. Lau GK, Piratvisuth T, Luo KX, Marcellin P, Thongsawat S, Cooksley G, Gane E, et al. Peginterferon Alfa-2a, lamivudine, and the combination for HBeAg-positive chronic hepatitis B. N Engl J Med 2005;352:2682-2695.

6. Janssen HL, van Zonneveld M, Senturk H, Zeuzem S, Akarca US, Cakaloglu Y, Simon C, et al. Pegylated interferon alfa- $2 \mathrm{~b}$ alone or in combination with lamivudine for $\mathrm{HBeAg}$-positive chronic hepatitis B: a randomised trial. Lancet 2005;365:123-129.

7. Buster EH, Hansen BE, Lau GK, Piratvisuth T, Zeuzem S, Steyerberg EW, Janssen HL. Factors that predict response of patients with hepatitis $B$ e antigen-positive chronic hepatitis $B$ to peginterferon-alfa. Gastroenterology 2009;137:2002-2009.

8. Erhardt A, Blondin D, Hauck K, Sagir A, Kohnle T, Heintges T, Haussinger D. Response to interferon alfa is hepatitis $B$ virus genotype dependent: genotype $A$ is more sensitive to interferon than genotype D. Gut 2005;54:1009-1013.

9. Kao JH, Wu NH, Chen PJ, Lai MY, Chen DS. Hepatitis B genotypes and the response to interferon therapy. J Hepatol 2000;33:998-1002.

10. Zhang $\mathrm{Y}, \mathbf{W u} \mathrm{Y}, \mathrm{Ye} \mathrm{S}$, Wang $\mathrm{T}$, Zhao $\mathrm{R}$, Chen $\mathrm{F}$, Abe $\mathrm{K}$, et al. The response to interferon is influenced by hepatitis $B$ virus genotype in vitro and in vivo. Virus Res 2013;171:65-70.

11. Li K, Chen Z, Kato N, Gale M, Jr., Lemon SM. Distinct poly $(\mathrm{I}-\mathrm{C})$ and virus-activated signaling pathways leading to interferon-beta production in hepatocytes. J Biol Chem 2005;280:16739-16747.

12. Luangsay S, Ait-Goughoulte $\mathbf{M}$, Michelet $\mathbf{M}$, Floriot $\mathrm{O}$, Bonnin M, Gruffaz M, Rivoire $\mathbf{M}$, et al. Expression and functionality of Toll- and RIG-like receptors in HepaRG cells. J Hepatol 2015;63:10771085.

13. Protzer U, Maini MK, Knolle PA. Living in the liver: hepatic infections. Nat Rev Immunol 2012;12:201-213.

14. Allweiss L, Volz T, Lutgehetmann M, Giersch K, Bornscheuer T, Lohse AW, Petersen J, et al. Immune cell responses are not required to induce substantial hepatitis $B$ virus antigen decline during pegylated interferon-alpha administration. J Hepatol 2014;60:500-507.

15. Lucifora J, Durantel D, Testoni B, Hantz O, Levrero M, Zoulim F. Control of hepatitis B virus replication by innate response of HepaRG cells. Hepatology 2010;51:63-72.

16. Verrier ER, Colpitts CC, Schuster C, Zeisel MB, Baumert TF. Cell Culture Models for the Investigation of Hepatitis B and D Virus Infection. Viruses 2016;8.

17. Allweiss L, Dandri M. Experimental in vitro and in vivo models for the study of human hepatitis B virus infection. J Hepatol 2016;64:S17-31.

18. Yan Z, Zeng J, Yu Y, Xiang K, Hu H, Zhou X, Gu L, et al. HBVcircle: A novel tool to investigate hepatitis B virus covalently closed circular DNA. J Hepatol 2017.

19. Lavender KJ, Gibbert K, Peterson KE, Van Dis E, Francois S, Woods T, Messer RJ, et al. Interferon Alpha Subtype-Specific Suppression of HIV-1 Infection In Vivo. J Virol 2016;90:6001-6013.

20. Sozzi V, Walsh R, Littlejohn M, Colledge D, Jackson K, Warner N, Yuen L, et al. In Vitro Studies Show that Sequence Variability Contributes to Marked Variation in Hepatitis B Virus Replication, Protein Expression, and Function Observed across Genotypes. J Virol 2016;90:10054-10064.

21. Cai D, Nie H, Yan R, Guo JT, Block TM, Guo H. A southern blot assay for detection of hepatitis B virus covalently closed circular DNA from cell cultures. Methods Mol Biol 2013;1030:151-161.

22. Gao W, Hu J. Formation of hepatitis B virus covalently closed circular DNA: removal of genome-linked protein. J Virol 2007;81:6164-6174. 
23. Lucifora J, Xia Y, Reisinger F, Zhang K, Stadler D, Cheng X, Sprinzl MF, et al. Specific and nonhepatotoxic degradation of nuclear hepatitis B virus cccDNA. Science 2014;343:1221-1228.

24. Tnani M, Bayard BA. Evidence for IRF-1-dependent gene expression deficiency in interferon unresponsive HepG2 cells. Biochim Biophys Acta 1999;1451:59-72.

25. Melen K, Keskinen P, Lehtonen A, Julkunen I. Interferon-induced gene expression and signaling in human hepatoma cell lines. J Hepatol 2000;33:764-772.

26. Jansen L, de Niet A, Makowska Z, Dill MT, van Dort KA, Terpstra V, Bart Takkenberg R, et al. An intrahepatic transcriptional signature of enhanced immune activity predicts response to peginterferon in chronic hepatitis B. Liver Int 2015;35:1824-1832.

27. Wu HL, Hsiao TH, Chen PJ, Wong SH, Kao JH, Chen DS, Lu JY, et al. Liver Gene Expression Profiles Correlate with Virus Infection and Response to Interferon Therapy in Chronic Hepatitis B Patients. Sci Rep 2016;6:31349.

28. Levin D, Harari D, Schreiber G. Stochastic receptor expression determines cell fate upon interferon treatment. Mol Cell Biol 2011;31:3252-3266.

29. Schreiber $\mathrm{G}$. The molecular basis for differential type I interferon signaling. J Biol Chem 2017;292:7285-7294.

30. Lavoie TB, Kalie E, Crisafulli-Cabatu S, Abramovich R, DiGioia G, Moolchan K, Pestka S, et al. Binding and activity of all human alpha interferon subtypes. Cytokine 2011;56:282-289.

31. Harper MS, Guo K, Gibbert K, Lee EJ, Dillon SM, Barrett BS, McCarter MD, et al. Interferonalpha Subtypes in an Ex Vivo Model of Acute HIV-1 Infection: Expression, Potency and Effector Mechanisms. PLoS Pathog 2015;11:e1005254.

32. Rijckborst V, Hansen BE, Cakaloglu Y, Ferenci P, Tabak F, Akdogan M, Simon K, et al. Early ontreatment prediction of response to peginterferon alfa-2a for $\mathrm{HBeAg-negative} \mathrm{chronic} \mathrm{hepatitis} B$ using HBsAg and HBV DNA levels. Hepatology 2010;52:454-461.

33. Fletcher SP, Chin DJ, Gruenbaum L, Bitter H, Rasmussen E, Ravindran P, Swinney DC, et al. Intrahepatic Transcriptional Signature Associated with Response to Interferon-alpha Treatment in the Woodchuck Model of Chronic Hepatitis B. PLoS Pathog 2015;11:e1005103.

34. Lebosse F, Testoni B, Fresquet J, Facchetti F, Galmozzi E, Fournier M, Hervieu V, et al. Intrahepatic innate immune response pathways are downregulated in untreated chronic hepatitis $B$. J Hepatol 2017;66:897-909.

35. Yi Z, Chen J, Kozlowski M, Yuan Z. Innate detection of hepatitis B and C virus and viral inhibition of the response. Cell Microbiol 2015;17:1295-1303.

36. Kao JH. Role of viral factors in the natural course and therapy of chronic hepatitis B. Hepatol Int 2007;1:415-430.

37. Zhang F, Tang X, Garcia T, Lok AS, Wang Y, Jia H, Qin Y, et al. Characterization of contrasting features between hepatitis $B$ virus genotype $A$ and genotype $D$ in small envelope protein expression and surface antigen secretion. Virology 2017;503:52-61.

38. Perales C, Beach NM, Gallego I, Soria ME, Quer J, Esteban JI, Rice C, et al. Response of hepatitis $C$ virus to long-term passage in the presence of alpha interferon: multiple mutations and a common phenotype. J Virol 2013;87:7593-7607.

39. Serre SB, Krarup HB, Bukh J, Gottwein JM. Identification of alpha interferon-induced envelope mutations of hepatitis $C$ virus in vitro associated with increased viral fitness and interferon resistance. J Virol 2013;87:12776-12793.

40. Chen J, Wu M, Zhang X, Zhang W, Zhang Z, Chen L, He J, et al. Hepatitis B virus polymerase impairs interferon-alpha-induced STA T activation through inhibition of importin-alpha5 and protein kinase C-delta. Hepatology 2013;57:470-482.

41. Lutgehetmann M, Bornscheuer T, Volz T, Allweiss L, Bockmann JH, Pollok JM, Lohse AW, et al. Hepatitis B Virus Limits Response of Human Hepatocytes to Interferon-alpha in Chimeric Mice. Gastroenterology 2011;140:2074-2083, 2083 e2071-2072. 
42. Mao R, Zhang J, Jiang D, Cai D, Levy JM, Cuconati A, Block TM, et al. Indoleamine 2,3dioxygenase mediates the antiviral effect of gamma interferon against hepatitis $B$ virus in human hepatocyte-derived cells. J Virol 2011;85:1048-1057.

43. Belloni L, Allweiss L, Guerrieri F, Pediconi N, Volz T, Pollicino T, Petersen J, et al. IFN-alpha inhibits HBV transcription and replication in cell culture and in humanized mice by targeting the epigenetic regulation of the nuclear cccDNA minichromosome. J Clin Invest 2012;122:529-537.

44. Liu F, Campagna M, Qi Y, Zhao X, Guo F, Xu C, Li S, et al. Alpha-interferon suppresses hepadnavirus transcription by altering epigenetic modification of cccDNA minichromosomes. PLoS Pathog 2013;9:e1003613.

45. Hong X, Kim ES, Guo H. Epigenetic Regulation of Hepatitis B Virus Covalently Closed Circular DNA: Implications for Epigenetic Therapy against Chronic Hepatitis B. Hepatology 2017.

46. Hiraga $N$, Imamura $M$, Hatakeyama $T$, Kitamura $S$, Mitsui $F$, Tanaka S, Tsuge $M$, et al. Absence of viral interference and different susceptibility to interferon between hepatitis $B$ virus and hepatitis C virus in human hepatocyte chimeric mice. J Hepatol 2009;51:1046-1054.

47. Schoggins JW, Wilson SJ, Panis M, Murphy MY, Jones CT, Bieniasz P, Rice CM. A diverse range of gene products are effectors of the type I interferon antiviral response. Nature 2011;472:481-485.

48. Liu CJ, Chen PJ, Lai MY, Chen TC, Wang HY, Huang WL, Kao JH, et al. Lack of interferon sensitivity-determining region in the genome of hepatitis B virus genotype Ba. Antivir Ther 2004;9:895-903.

49. Israelow B, Narbus CM, Sourisseau M, Evans MJ. HepG2 cells mount an effective antiviral interferon-lambda based innate immune response to hepatitis $C$ virus infection. Hepatology 2014;60:1170-1179.
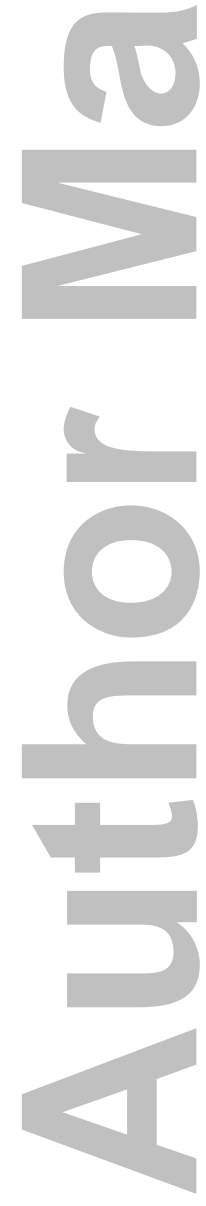


\section{Figure legends}

Figure 1. Infection of PHH by $\mathrm{HBV}$ genotype A2, B5, C2 and D3 respectively. PHH were infected with HBV genotype A2, B5, C2 or D3 particles at same viral genome equivalents (1000 vge) per cell. HepAD38-derived D (250 vge) was set as control. HBsAg, HBeAg and HBV DNA levels in medium at indicated time points post viral infection were measured by CLIA ELISA or quantified by qPCR(A). HBsAg (green) expression at day 12 was detected by immunofluorescence (B). HBV cccDNA levels in PHH infected with different HBV genotype was examined by Southern blot $(\mathrm{C})$, and the cccDNA was verified with heat denaturation or further EcoRI digestion before electrophoresis for Southern blot analysis.

Figure 2. Anti-HBV activity of IFN-a on HBV genotype A2/B5/C2/D3/D in PHH. The anti-HBV effect of IFN- $\alpha(20,100,500 \mathrm{U} / \mathrm{ml})$ was evaluated with two different treatments (A). $\mathrm{PHH}$ infected with HBV genotype A2/B5/C2/D3 were either treated with IFN- $\alpha$ from day 3 to day 12 post HBV infection for 9-days treatment (B), or pretreated with IFN- $\alpha$ for 24 hours before viral infection (D). Extracellular HBsAg, HBeAg and HBV DNA levels with IFN- $\alpha$ treatments were evaluated at day12. Cell viability of PHH with 9-days IFN- $\alpha$ post viral infection was determined by CCK 8 kit $(\mathrm{C})$. The antiviral effect of IFN- $\alpha(20 \mathrm{U} / \mathrm{ml})$ associated with HBV replication levels were also checked on HBV genotype D with increased viral inoculum (E). Statistical analysis was performed with Student's t test. Data are shown as mean $\pm \mathrm{SD}(\mathrm{n}=3) . * *, \mathrm{P}<0.01 ; *, \mathrm{P}<0.05 ; \mathrm{ns}, \mathrm{P}>0.05$.

Figure 3. Effect of IFN- $\alpha$ on cccDNA of HBV genotype A2/B5/C2/D3/D. IFN- $\alpha$ (500 U/ml) was used to treat HBV genotype A2/B5/C2/D3 infected PHH from 3 days to 12 days post infection, the cccDNA (Hirt DNA) extracted were analyzed by qPCR with specific primers (A). PEG-IFN- $\alpha-2 a$ was used to examine its effect on cccDNA with multiple doses (B) by Southern blot.

Figure 4. Anti-HBV activity of IFN- $\alpha$ in dHepaRG and HepG2-NTCP cells. dHepaRG cells were infected with HBV genotype A2/B5/C2/D3 (1000 vge) respectively and further treated with IFN- $\alpha(20,100,500 \mathrm{U} / \mathrm{ml})$ for 9 days from day 3 post viral infection (A). The anti-HBV effect of IFN- $\alpha$ on secretion of HBsAg, HBeAg and HBV DNA at day 12 were evaluated, and no cytotoxicity was observed after treatment (B). Anti-HBV effect of IFN- $\alpha$ $(20,100,500 \mathrm{U} / \mathrm{ml})$ in HepG2-NTCP on genotype D that derived from HepAD38 cells was evaluated and compared with the effect in PHH and dHepaRG cells (C). Statistical analysis was performed with Student's $t$ test. Data are shown as mean $\pm \operatorname{SD}(\mathrm{n}=3)$. **, $\mathrm{P}<0.01$; *, $\mathrm{P}<0.05 ; \mathrm{ns}, \mathrm{P}>0.05$.

Figure 5. Activation of IFN- $\alpha$ signaling and ISGs expression in PHH, dHepaRG and HepaG2-NTCP cells. Activation of JAK/STAT, ISGs and other innate immunity markers by various concentrations of IFN- $\alpha(0.4,2,10$ and $50 \mathrm{ng} / \mathrm{ml})$ for 0.5 hour or 24 hours in HepG2NTCP, dHepaRG and PHH were examined by Western blot analysis or qRT-PCR (A, B, C). Expression levels of indicated proteins in PHH, dHepaRG and HepG2-NTCP cells were also examined (D). IFN- $\alpha$ (2 ng/ml)-induced ISG20 and A3G expression was detected in the absence or presence of CHX (50 $\mu \mathrm{g} / \mathrm{ml})$ in PHH and HepG2-NTCP cells (E).

Figure 6. Association between the cellular interferon response and the efficacy of IFN-a against HBV. The effect of IFN- $\alpha$ treatment on the secretion of HBV DNA from PHH was evaluated in the absence or presence of the JAK inhibitor I (Tofacitinib, $5 \mu \mathrm{M}$ ) (A, B). IFN$\alpha 14-$ or IFN- $\alpha 2$-induced expression of indicated genes (C), and the inhibitory effect of IFNs on HBV replication were examined in HepG2-NTCP cells (D). Statistical analysis was performed with Student's $t$ test. Data are shown as mean $\pm \mathrm{SD}(\mathrm{n}=3)$. **, $\mathrm{P}<0.01$; *, $\mathrm{P}<0.05 ; \mathrm{ns}, \mathrm{P}>0.05$. 


\section{Acknowledgements}

We thank Jianhua Li, Zhigang Yi and Xiaonan Zhang for valuable comments and suggestions.

\section{Authors contributions:}

Yuan ZH, Chen JL, Shen F designed the research; Shen F, Li YM, Wang Y, Sozzi V, Liu JX and Chen JL performed the research; Yuan ZH and Chen JL supervised the research; Yuan ZH, Revill P, Gao L, Yang G, Sutter K, Dittmer U and Lu MJ provided materials; all authors analyzed the data; Shen F and Chen JL wrote the paper; Yuan ZH, Sozzi V, Revill P, Gao L, Lu MJ, Sutter K and Dittmer U revised the paper.

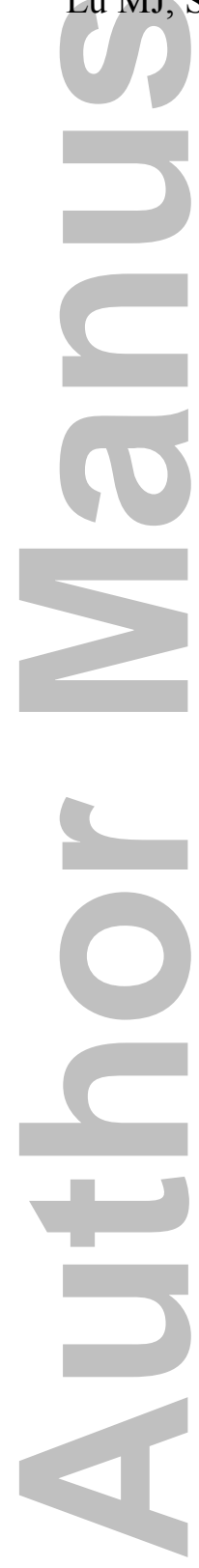




\section{Table 1. Comparison of $\mathrm{IC}_{50}$ concentrations $(\mathrm{U} / \mathrm{ml})$ for $\mathrm{IFN}-\alpha$ against $\mathrm{HBV}$ genotype $\mathrm{A} 2 / \mathrm{B5} / \mathrm{C2} / \mathrm{D3}$ in three hepatocyte cell culture-based infection systems.}

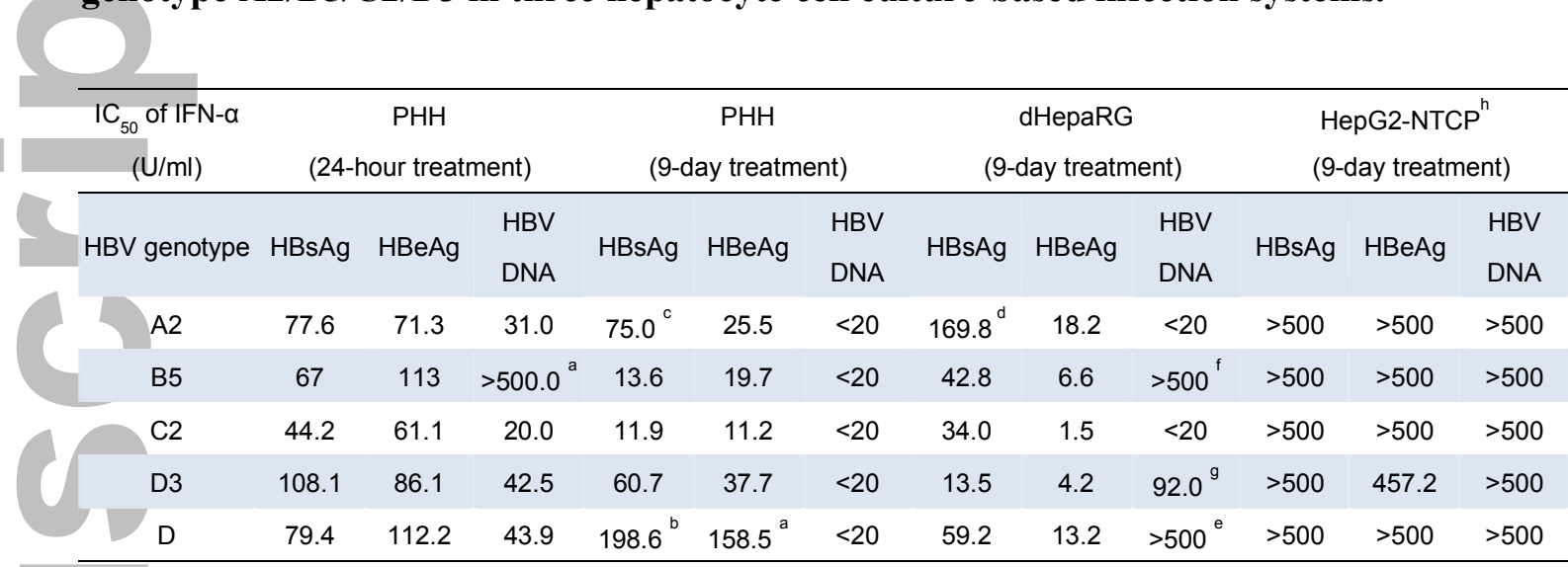

$\mathrm{IC}_{50}$ values were calculated with Graphpad Prism, statistical analysis was performed by two-way ANOVA (IFN- $\alpha$ concentration and HBV genotypes) for multiple comparisons.

${ }^{a} \mathrm{P}<0.01$, as compared with other viruses. ${ }^{b} \mathrm{P}<0.01$, as compared with $\mathrm{B} 5, \mathrm{C} 2$ and $\mathrm{D} 3{ }^{\mathrm{c}}{ }^{\mathrm{P}} \mathrm{P}<0.05$, as compared with $\mathrm{B} 5, \mathrm{C} 2$ and $\mathrm{D} 3$. ${ }^{d} \mathrm{P}<0.05$, as compared with other viruses. ${ }^{e} \mathrm{P}<0.01$, as compared with $\mathrm{A} 2, \mathrm{C} 2$ and $\mathrm{D} 3{ }^{\mathrm{f}}{ }^{\mathrm{P}} \mathrm{P}<0.01$, as compared with $\mathrm{A} 2$ and $\mathrm{C} 2$. ${ }^{\mathrm{g}}$ $\mathrm{P}<0.05$, as compared with $\mathrm{A} 2$ and $\mathrm{C} 2$. $\mathrm{p}$ value greater than 0.05 is not displayed. ${ }^{\mathrm{h}}$ Productive replication was only established in HepG2-NTCP cells using the HepAD38-derived virus. 

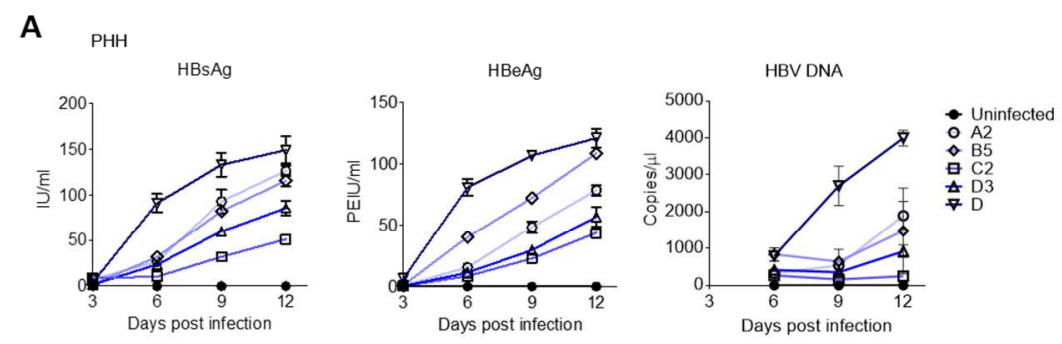

B Day $12 \mathrm{pi}$

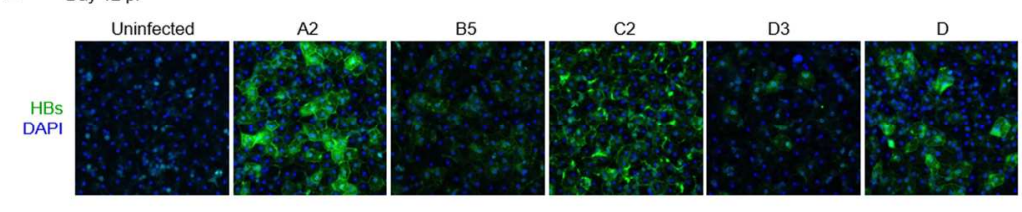

C Hirt DNA

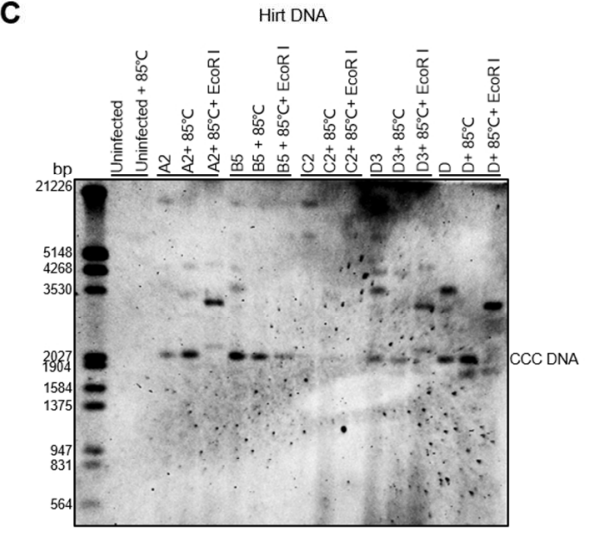

Figure 1. Infection of PHH by HBV genotype A2, B5, C2 and D3 respectively. $101 \times 127 \mathrm{~mm}(300 \times 300$ DPI $)$ 
A

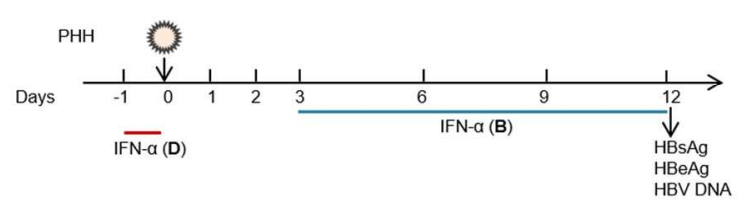

B
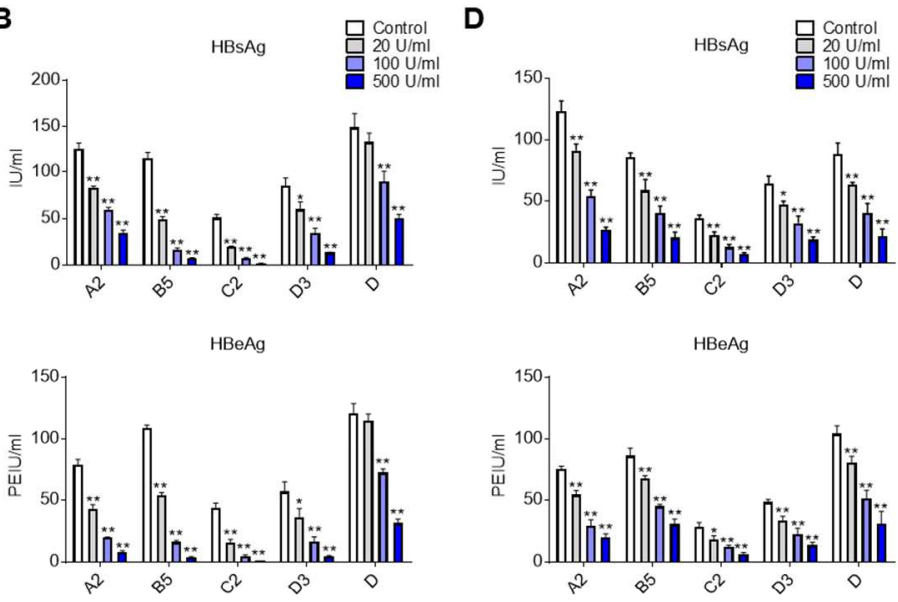

HBV DNA
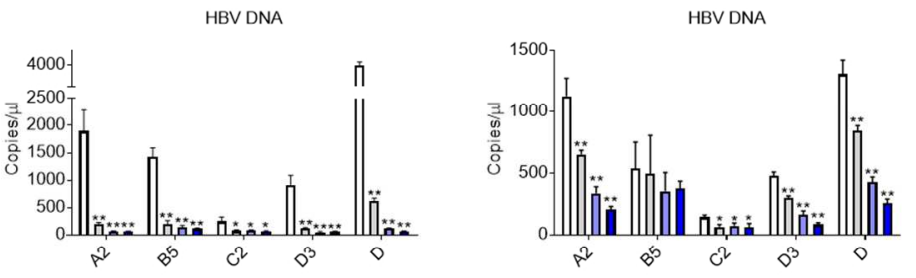

C

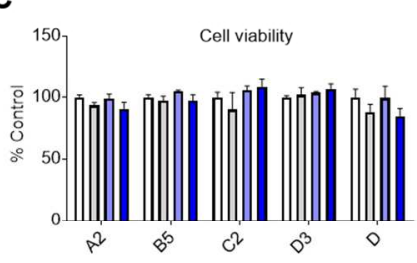

E

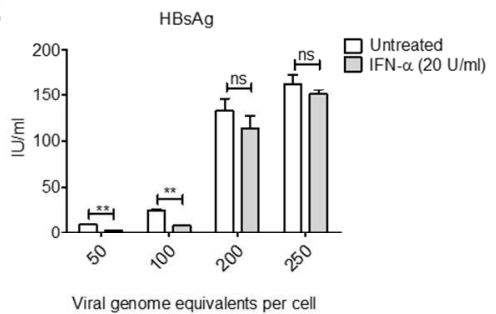

Figure 2. Anti-HBV activity of IFN-a on HBV genotype A2/B5/C2/D3/D in PHH. $101 \times 127 \mathrm{~mm}(300 \times 300 \mathrm{DPI})$ 
A
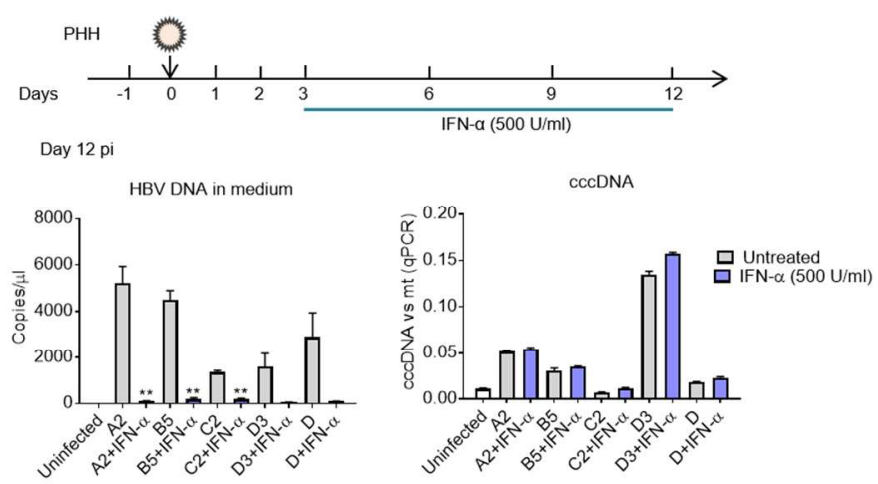

B

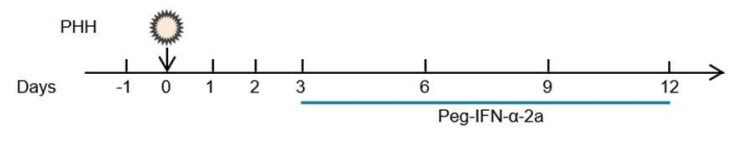

Day 12 pi
HBV markers in medium

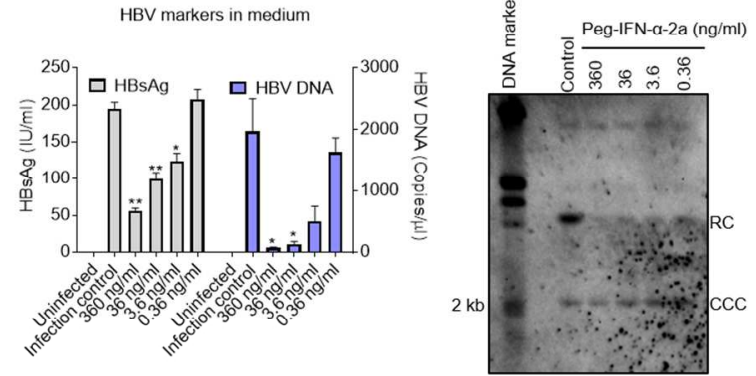

Figure 3. Effect of IFN-a on cccDNA of HBV genotype A2/B5/C2/D3/D in PHH.

$101 \times 127 \mathrm{~mm}(300 \times 300 \mathrm{DPI})$ 


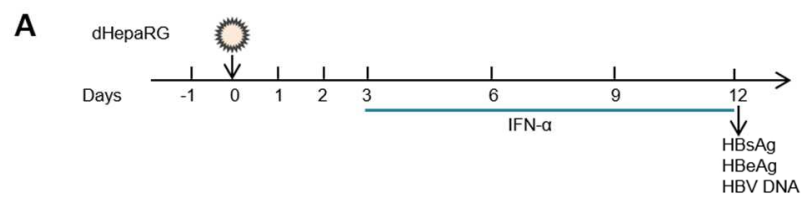

B
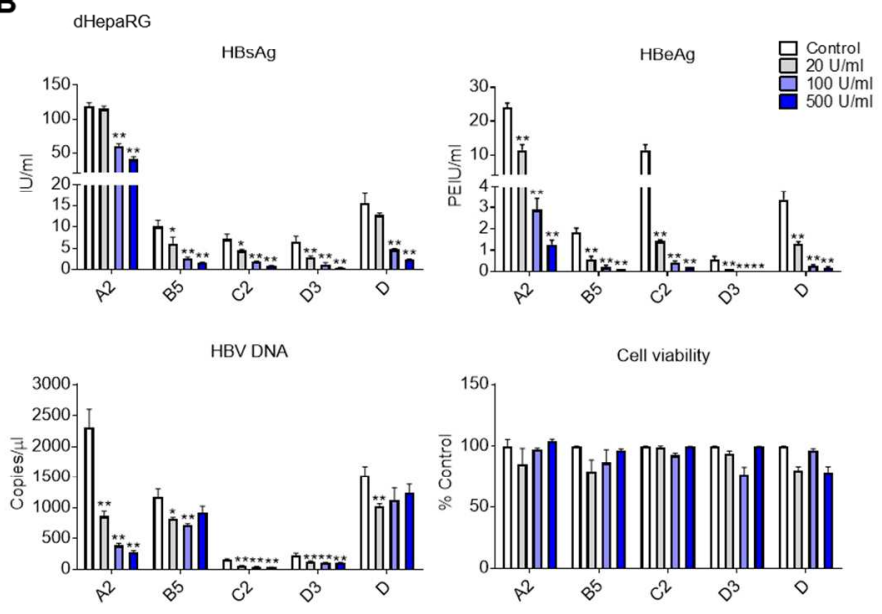

C

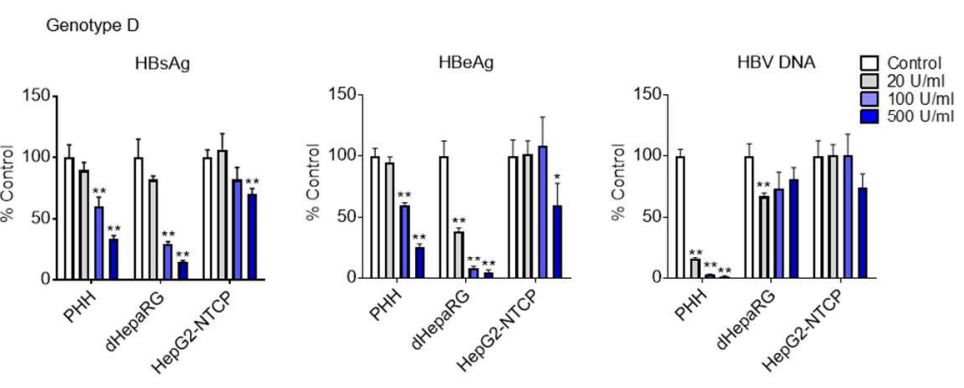

Figure 4. Anti-HBV activity of IFN-a in dHepaRG and HepG2-NTCP cells. $101 \times 127 \mathrm{~mm}(300 \times 300 \mathrm{DPI})$ 
A

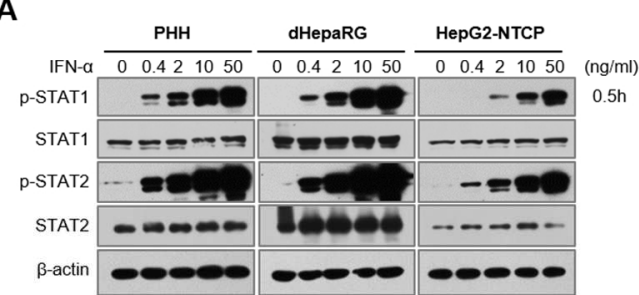

D

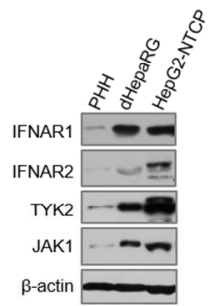

B
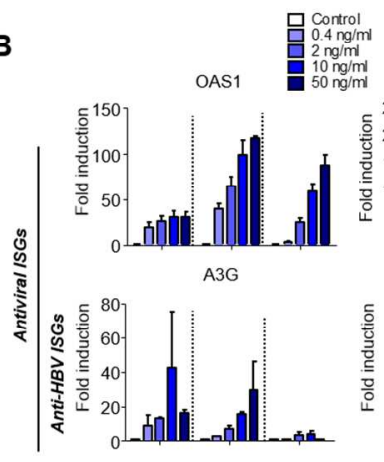

$$
\begin{aligned}
& \\
& \mathrm{ml} \\
& \mathrm{g} / \mathrm{ml}
\end{aligned} \quad \text { IFITM1 }
$$

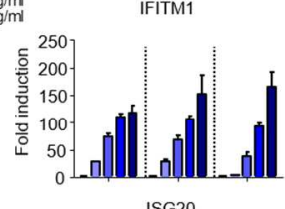

E

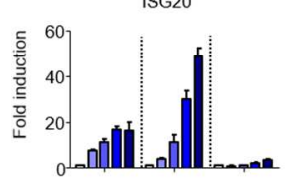

GBP5
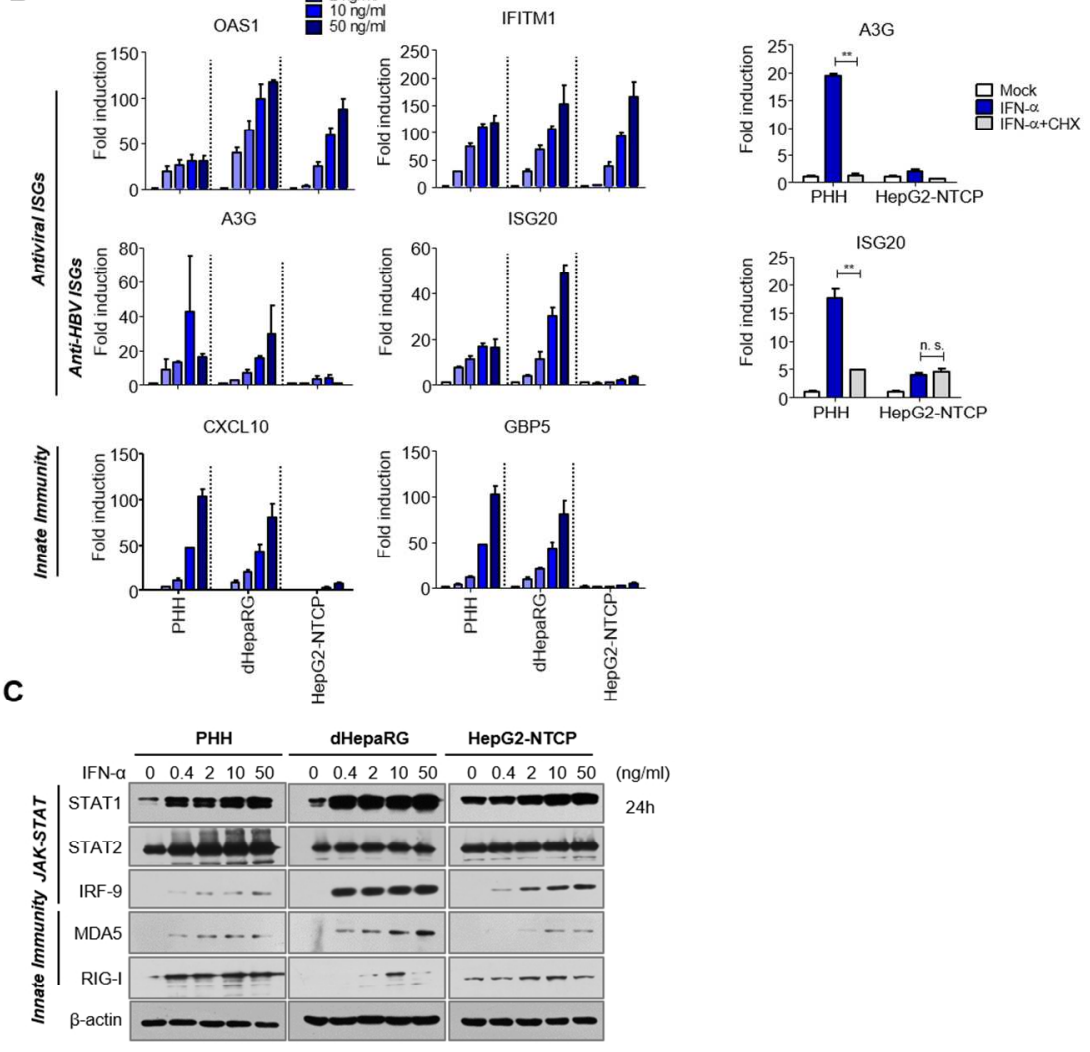

Figure 5. Activation of IFN-a signaling and ISGs expression in PHH, dHepaRG and HepaG2-NTCP cells. $101 \times 127 \mathrm{~mm}(300 \times 300 \mathrm{DPI})$

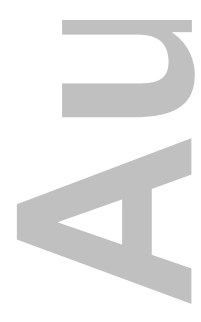




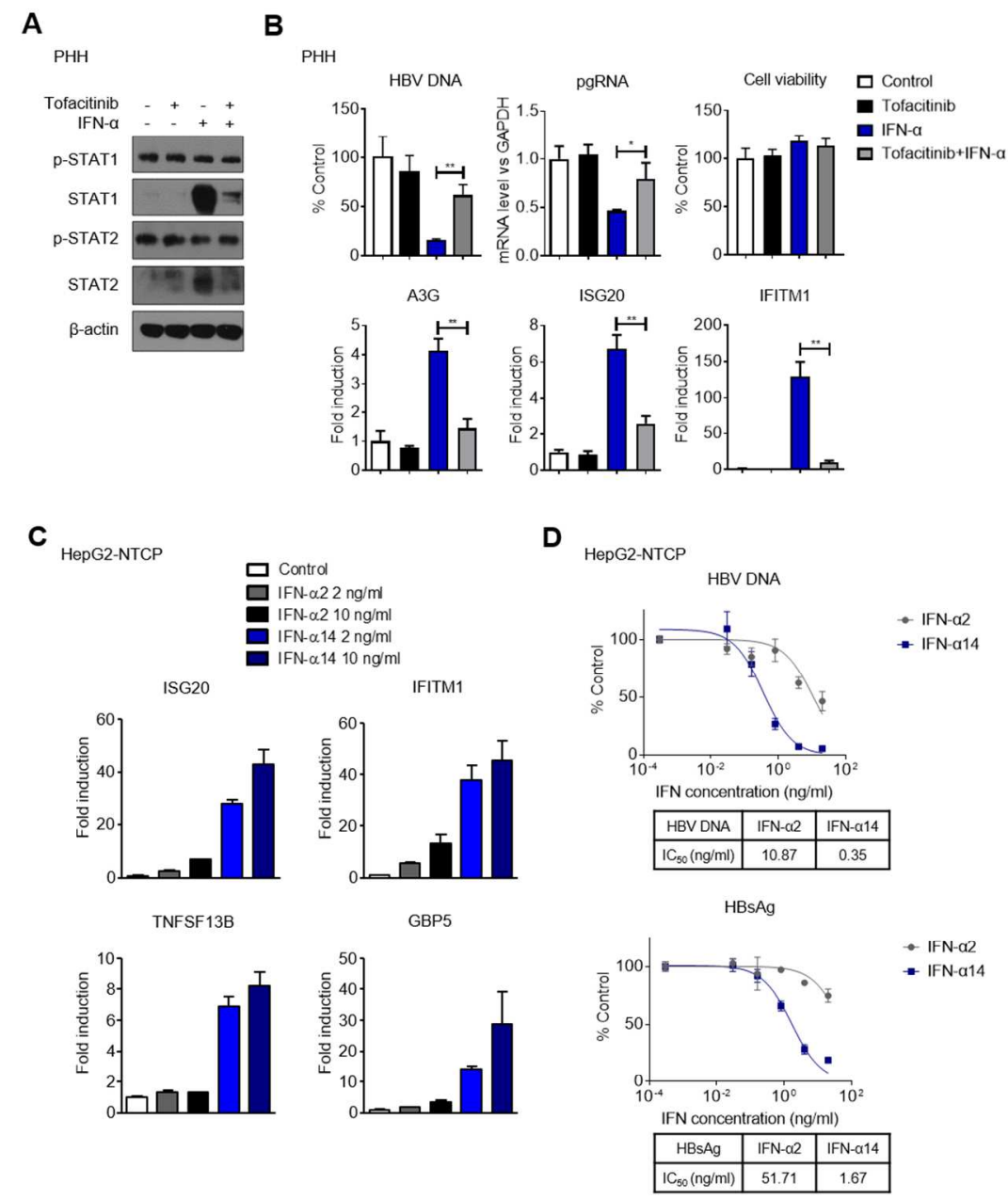

Figure 6. Association between the cellular interferon response and the efficacy of IFN-a against HBV. $101 \times 127 \mathrm{~mm}(300 \times 300$ DPI $)$

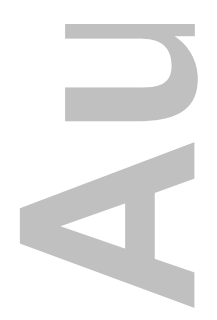




\section{Supplementary material}

Hepatitis B Virus Sensitivity to Interferon-a in Hepatocytes is More Associated with Cellular Interferon Response than with Viral Genotype

Fang Shen, Yaming Li, Yang Wang, Vitina Sozzi, Peter A Revill, Jiangxia Liu, Lu Gao, Guang Yang, Mengji Lu, Kathrin Sutter, Ulf Dittmer, Jieliang Chen and Zhenghong Yuan

\section{Contents}

Supplementary methods

Cell culture, antibodies and reagents

Plasmids, virus production, in vitro viral infection

Supplementary Figures

Supplementary Fig. 1

Supplementary Fig. 2

Supplementary Fig. 3

Supplementary Fig. 4

Supplementary Fig. 5

Supplementary Fig. 6

Supplementary Tables

Supplementary Table 1

Supplementary Table 2

Supplementary Table 3

\section{References}

\section{Graphical Abstract}

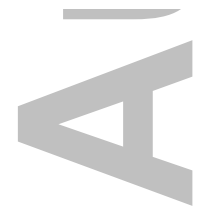




\section{Supplementary methods}

\section{Cell culture, antibodies and reagents}

The human hepatoma derived cell line HepG2 (purchased from ATCC) was cultured in DMEM/F12 (Invitrogen) supplemented with 10\% fetal bovine serum (Invitrogen), 2 mM Lglutamine, $100 \mathrm{U} / \mathrm{ml}$ penicillin, and $100 \mathrm{mg} / \mathrm{ml}$ streptomycin at $37^{\circ} \mathrm{C}$ in a $5 \% \mathrm{CO} 2$ incubator. Proliferating HepaRG cells were purchased from Biopredic International (Rennes, France). HepaRG cells were amplified and differentiated following the manufacturer's protocol. HepG2-NTCP (kindly provided by Prof. Stephan Urban, University Hospital Heidelberg, Germany) and HepAD38 (kindly provided by Prof. Christoph Seeger, Fox Chase Cancer Center, USA) were cultured as previously described. Primary human hepatocytes (PHH) (purchased from Bioreclamation IVT) were cultured in maintenance medium (Life Technologies) containing 2\% DMSO and 2\% FBS. All cultures were incubated at $37^{\circ} \mathrm{C}$ in a humidified 5\% CO2 incubator. Antibodies used here were summarized in Table S2, and qPCR primers used were synthesized by Biosune, and primer sequences were listed in Table S3.

\section{Plasmids, virus production, in vitro viral infection}

Plasmids pUC57-HBV 1.3 mer of different HBV genotypes ( A2, B1, B2, B5, D3) were constructed by Prof. Peter A Revill and Dr. Vitina Sozzi, pHBV C2 (C3.8) was described previously [1]. HBV different genotype viruses were produced by transient transfection of HepG2 cells with the corresponding plasmids as described previously [2]. Briefly, HBV plasmid was transiently transfected to HepG2 cells with X-tremeGENE HP DNA Transfection Reagent (Roche), the culture medium was refreshed at 24 hours post transfection with DMEM/F12 medium supplemented with 10\% FBS, L-Glutamine, NEAA, P/S, and 1\% DMSO and then was collected every 4 days for 12 days. The HBV particles released in the culture medium were concentrated through a $20 \%$ sucrose gradient by ultracentrifugation at 32,000 rpm for 18 hours, followed by resuspension in the fresh culture medium. HBV genotype D was derived from HepAD38 cells, the cell culture supernatant from HepAD38 cells after removal of tetracycline were collected every 3 days for 12 days, then was filtered through a $0.45 \mu \mathrm{m}$ filter and precipitated with $8 \%$ PEG8000 overnight at $4{ }^{\circ} \mathrm{C}$, the precipitates were centrifuged at $4000 \mathrm{~g}$ for $60 \mathrm{~min}$. The levels of HBV DNA in concentrated HBV particles were determined by $\mathrm{qPCR}$ with HBV genotype universal primers and probe. The PHH, dHepaRG and HepG2NTCP cells were infected with each HBV genotype virus at same viral genome equivalent GE/cell in the presence of 4\% PEG8000 for 16 hours as described previously [3, 4, 5]. 


\section{Supplementary Figures}

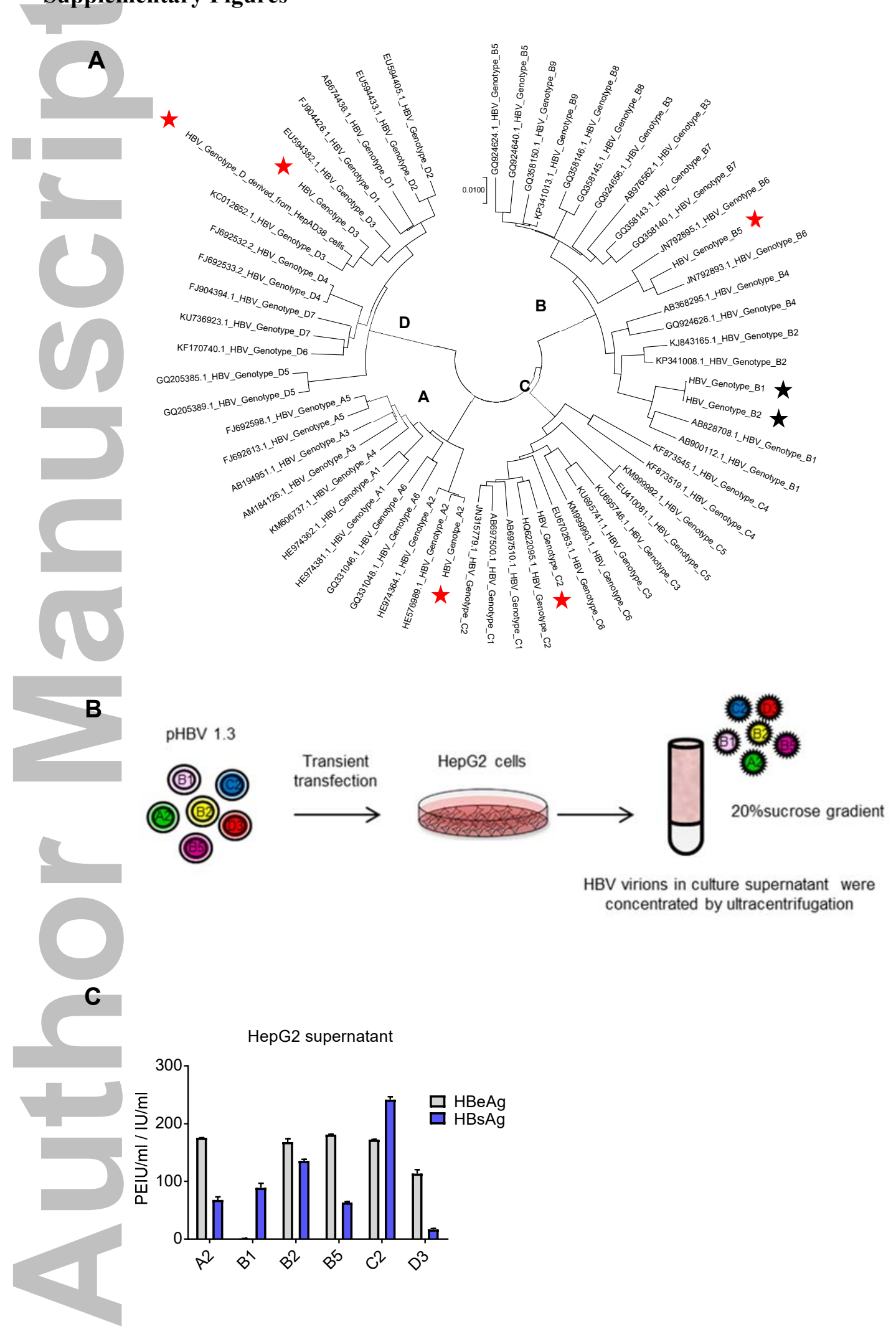



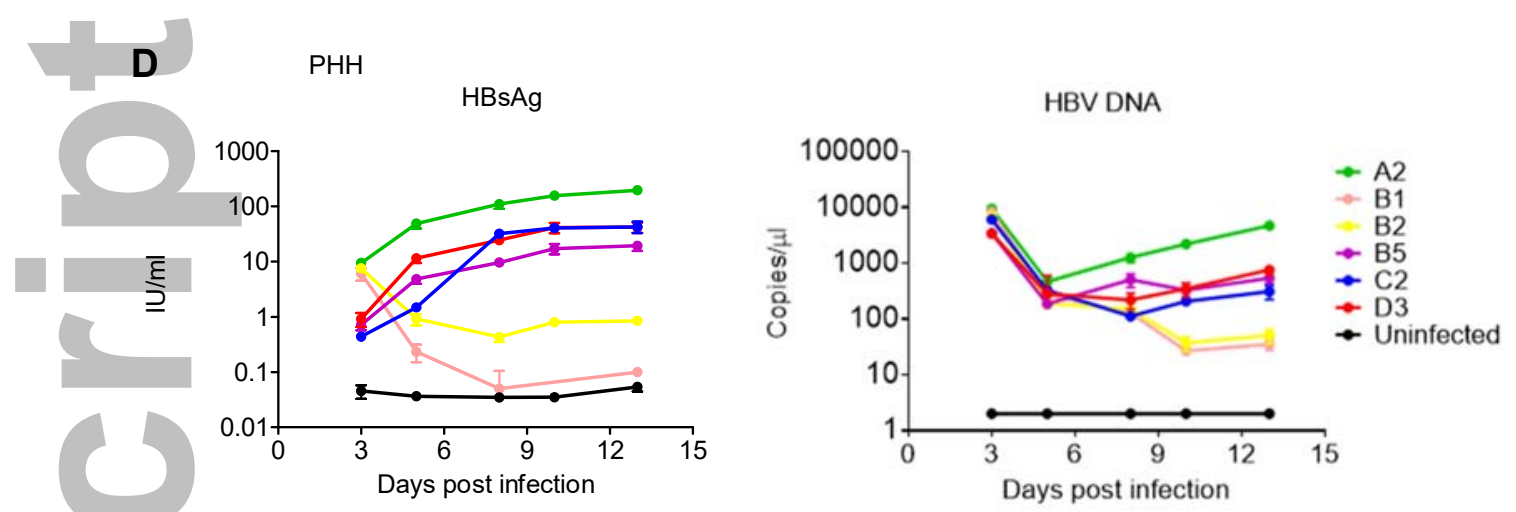

Supplementary Fig. 1 Generation of HBV virions of genotype A to D in HepG2 cells and infection efficiency in primary human hepatocyte (PHH).

Phylogenetic comparison of a number of HBV genotypes (A-D) used (marked with star) with representative subtypes obtained from GenBank (A), the accession numbers are indicated for the reference isolates and followed by subtype. HBV particles of different HBV genotypes were produced in vitro by transient expression of cloned HBV DNA into HepG2 cells (B), expression levels of HBsAg and HBeAg in HepG2 after transfection were measured (C), and HBV virions from culture medium were further concentrated by centrifugation. The infection efficiency of produced different HBV genotype virions were tested in primary human hepatocytes $(\mathrm{PHH})(\mathrm{D})$.

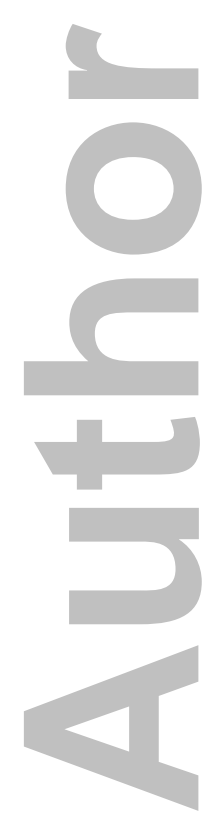




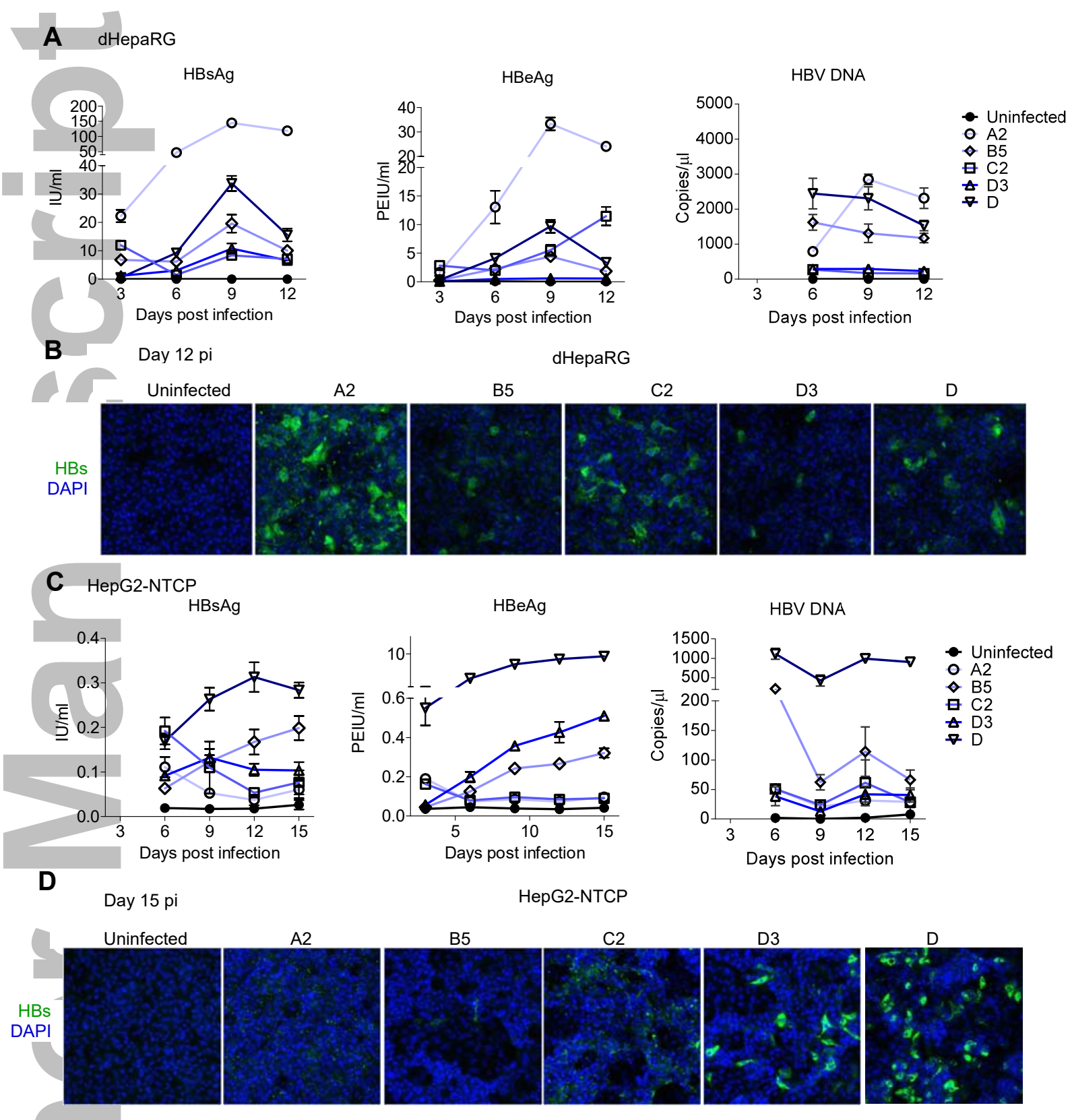

Supplementary Fig. 2 Infection of dHepaRG and HepG2-NTCP cells by HBV genotype

A2, B5, C2 and D3 respectively. dHepaRG and HepG2-NTCP cells were infected respectively with HBV genotype A2, B5, C2 and D3 particles at same viral genome equivalents (1000 vge) per cell. D (derived from HepAD38 cells, 250 vge/cell) was set as a control. HBsAg and $\mathrm{HBeAg}$ secretion into culture supernatant at indicated time points were assessed by CLIA, extracellular HBV DNA was quantified by qPCR with a HBV plasmid standard (A, C). HBsAg (green) expression levels at indicated time in dHepaRG and HepG2-NTCP cells were detected by immunofluorescence (B, D). 

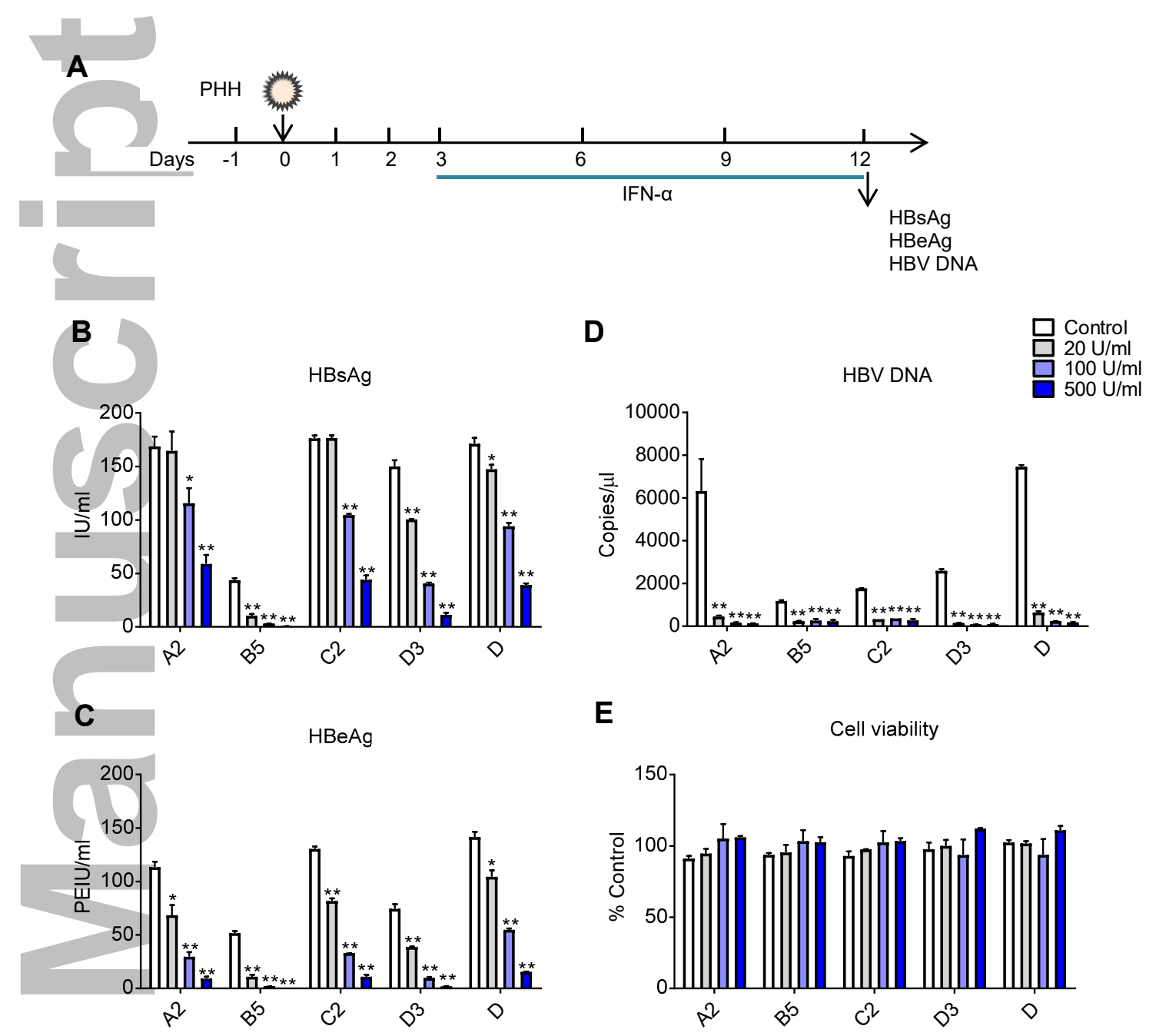

E
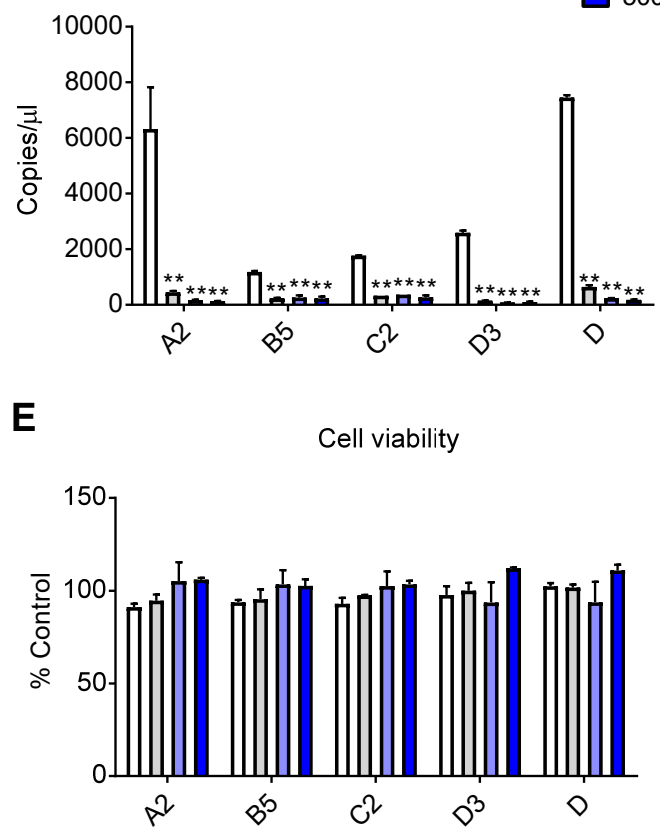

Supplementary Fig. 3 Anti-HBV activity of IFN- $\alpha$ on HBV genotype A2/B5/C2/D3/D was confirmed in PHH from another donor. $\mathrm{PHH}$ were infected with HBV genotype A2/B5/C2/D3 (1000 vge) and further treated with IFN- $\alpha(20,100,500 \mathrm{U} / \mathrm{ml})$ for 9 days from day 3 post viral infection (A). Secreted HBsAg, HBeAg and HBV DNA at day 12 were measured by CLIA ELISA or quantified by qPCR (B, C, D). Cell viability after IFN treatment were measured by CCK8 kit (E). Statistical analysis was performed with Student's t test. Data are shown as mean $\pm \mathrm{SD}(\mathrm{n}=3)$. **, $\mathrm{P}<0.01{ }^{*}, \mathrm{P}<0.05 ; \mathrm{ns}, \mathrm{P}>0.05$. 

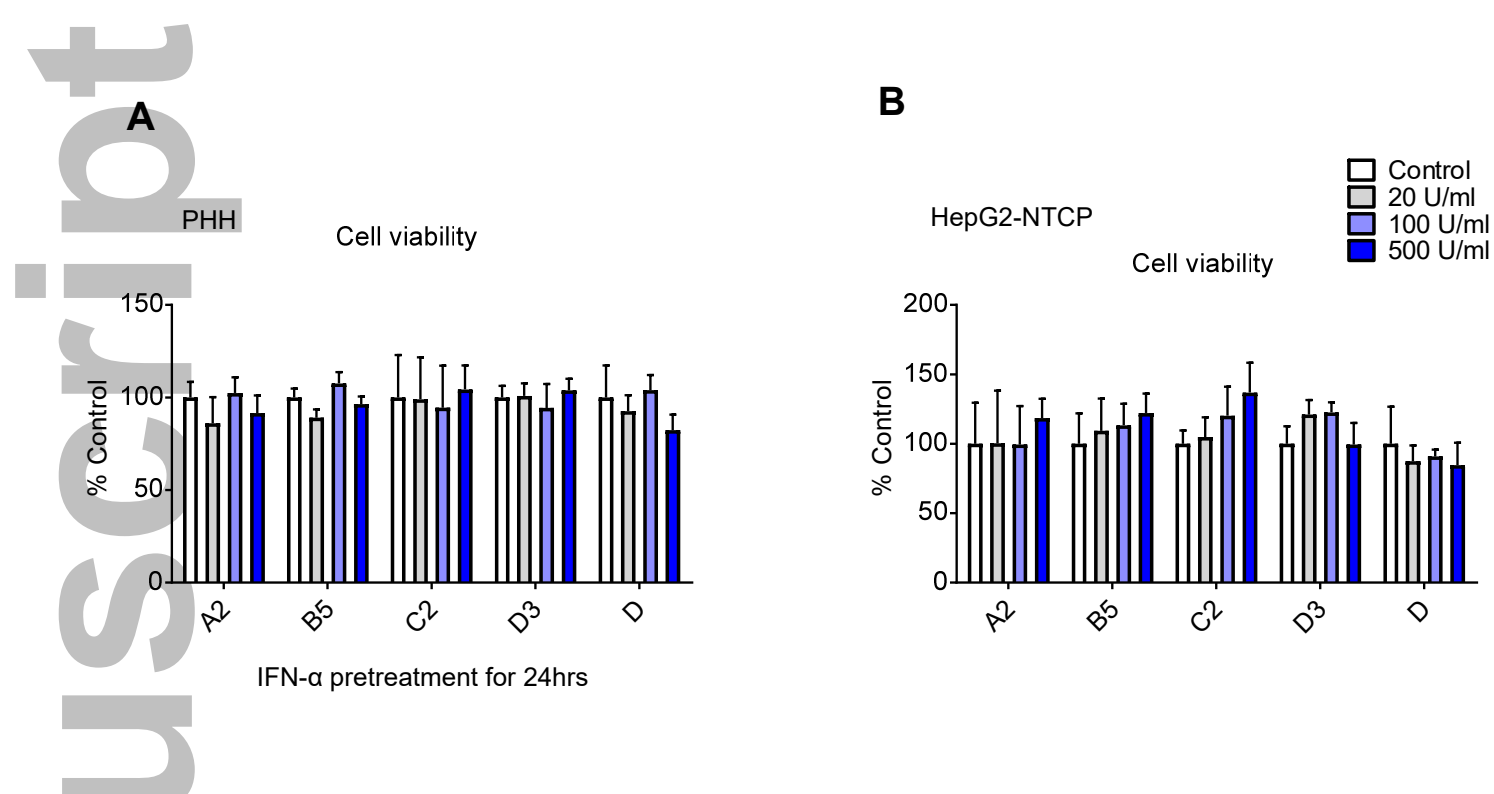

IFN- $\alpha$ pretreatment for $24 \mathrm{hrs}$

Supplementary Fig. 4 Cell viability of PHH and HepG2-NTCP cells after IFN- $\alpha$ treatment. The cell viability with 24 -hour treatment by IFN- $\alpha(20,100,500 \mathrm{U} / \mathrm{ml})$ before HBV infection in PHH (A), or with 9-days treatment by IFN- $\alpha$ in HepG2-NTCP cells were measured at day 12 post infection by CCK-8 kit (B).
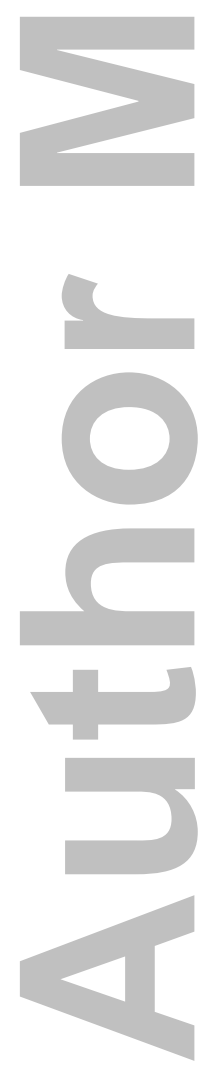

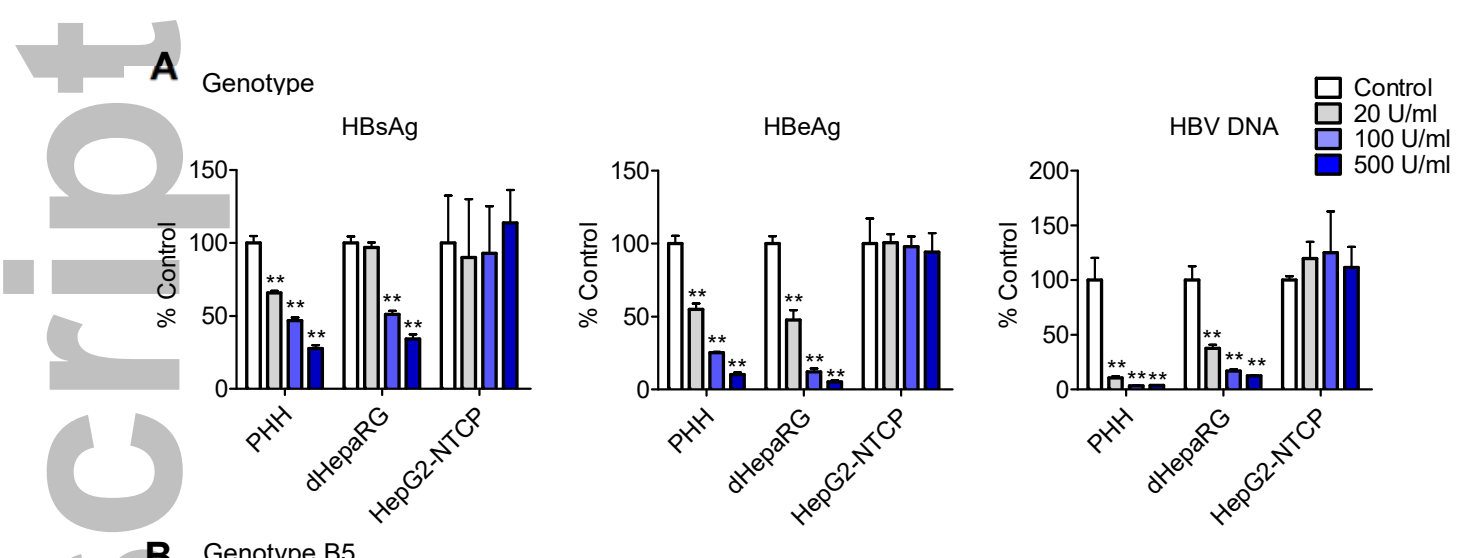

B Genotype B5
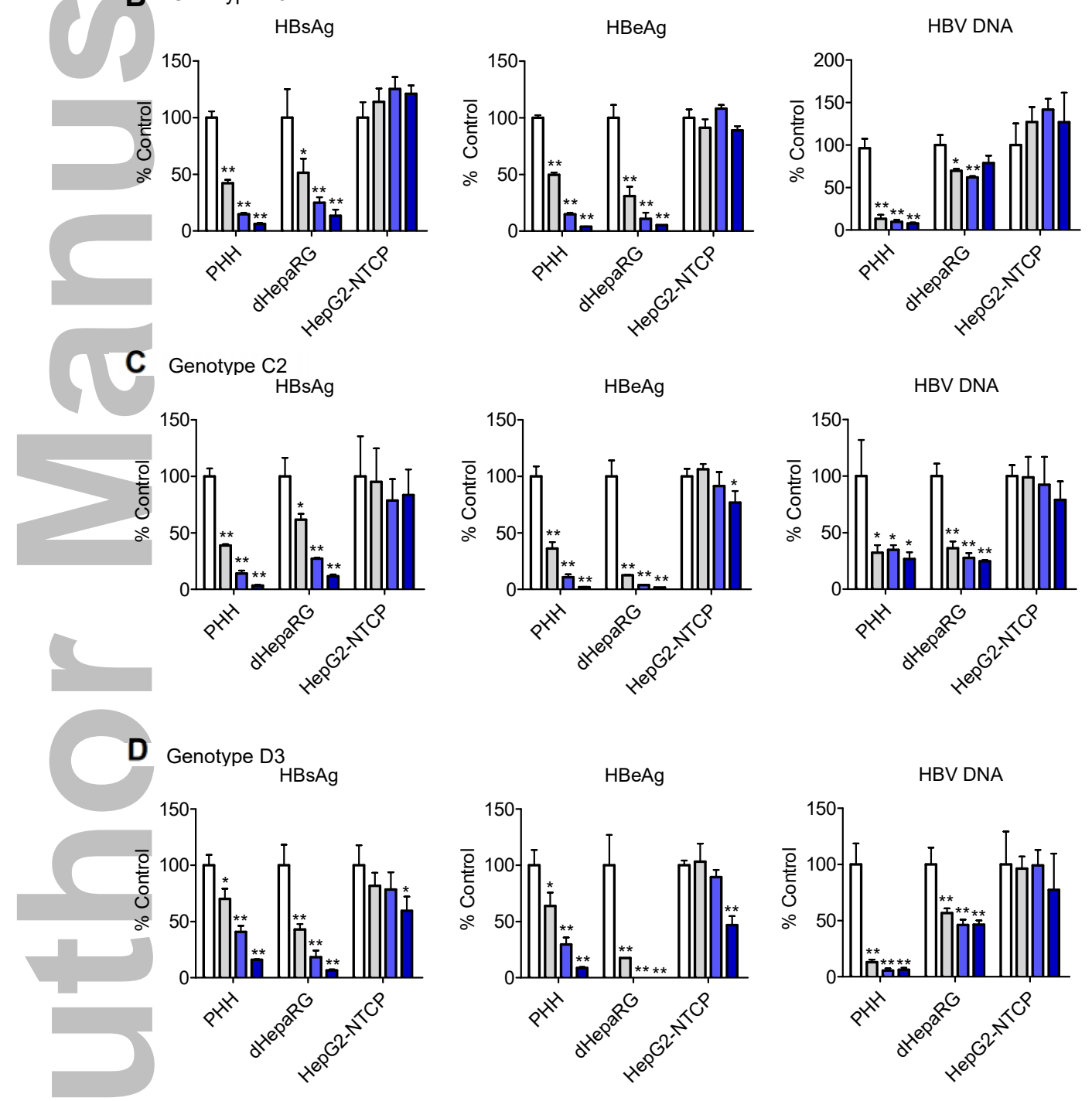

Supplementary Fig. 5 Comparison of IFN-a against each HBV genotype among three hepatocyte cell culture systems. Anti-HBV effect of IFN- $\alpha$ on each genotype (A2, B5, C2 and D3) in three cell infection models were compared in parallel (A, B, C and D). 


\section{A}

Genes examined in this study

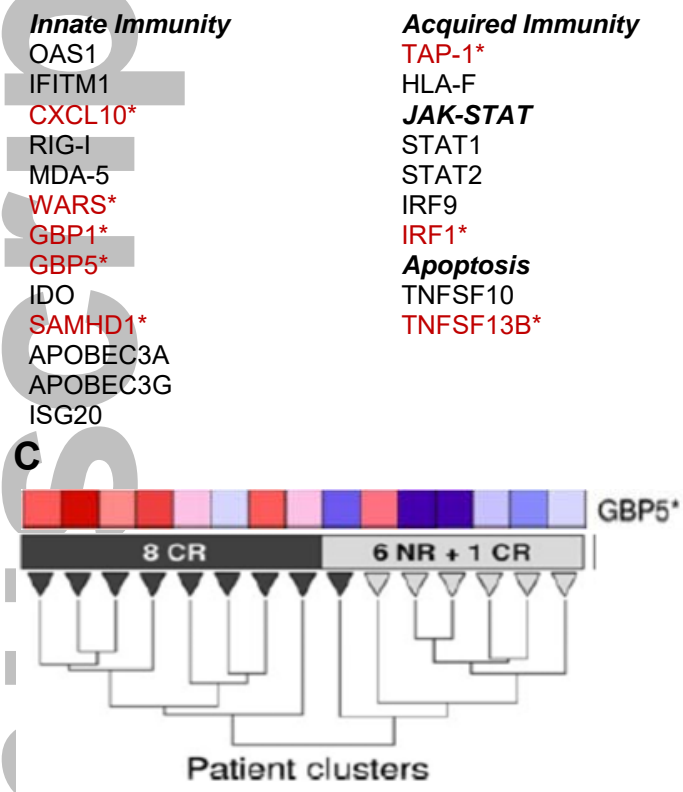

Jansen, L., et al. An intrahepatic transcriptional signature of enhanced immune activity predicts response to peginterferon in chronic hepatitis B. Liver Int, 35(7): 18241832 (2015).
B

*Significant differentially expressed genes between 7 paired liver biopsy samples of $\mathrm{CHB}$ patients taken before (BRB) and 6 months after (BRA) successful IFNa treatment, which, at the same time, overlapped with the differentially expressed genes between pretreatment biopsy samples of 11 IFNa responders (BR) and 11 nonresponders (BN).

\begin{tabular}{|c|c|c|}
\hline & \multicolumn{2}{|c|}{ log2(fold change) } \\
\hline & BRB vs. BRA $^{*}$ & BR vs. BN $^{\#}$ \\
\hline CXCL10 & 2.25 & 0.94 \\
\hline WARS & 0.8 & 0.7 \\
\hline GBP1 & 1.09 & 0.82 \\
\hline GBP5 & 0.81 & 0.8 \\
\hline SAMHD1 & 0.75 & 0.71 \\
\hline TAP1 & 0.87 & 0.6 \\
\hline STAT1 & 1.57 & n.s. \\
\hline IRF1 & 0.7 & 0.63 \\
\hline TNFSF13B & 0.75 & 0.71 \\
\hline
\end{tabular}

Wu H, et al. Liver Gene Expression Profiles Correlate with Virus Infection and Response to Interferon Therapy in Chronic Hepatitis B Patients. Sci Rep, DOI: 10.1038/srep31349 (2016).

D
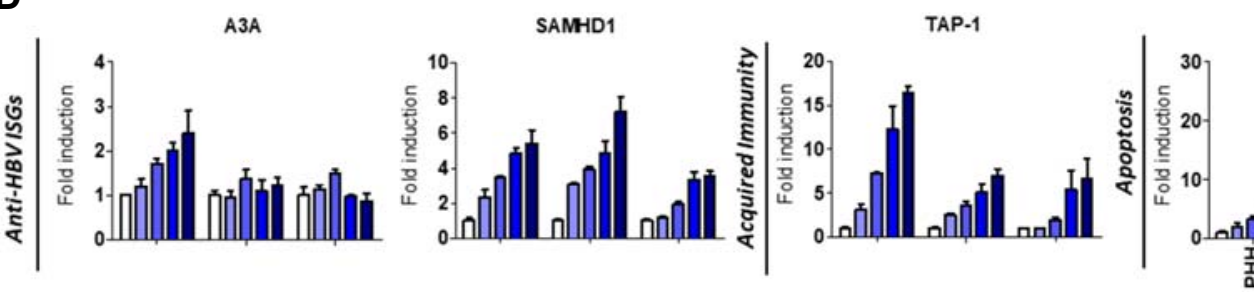

TNF SF13B
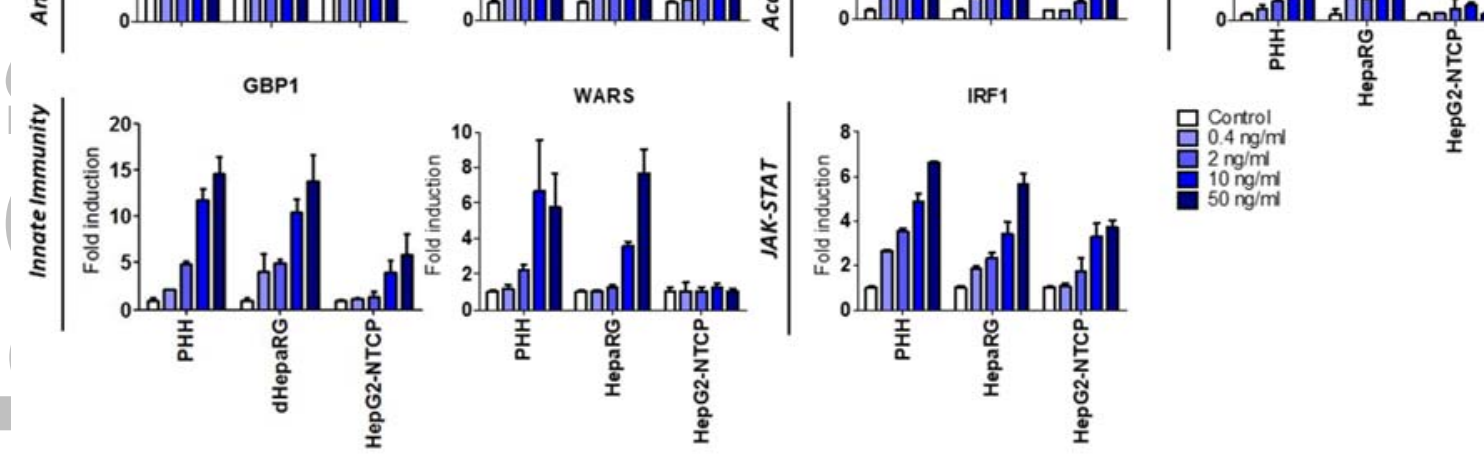

Supplementary Fig. 6 Genes that are reported to be associated with IFN- $\alpha$ responses. The expression of several genes in PHH, dHepaRG and HepG2-NTCP cells were examined in this study (A, D). Significant differentially expressed genes between 7 paired liver biopsy samples taken before and 6 months after successful IFN- $\alpha$ treatment (B). Studies from Jansen, L., et al [6], also identified GBP5 as a gene that is differentially expressed between the IFN responders and non-responders in baseline liver biopsies of CHB patients (C). 
Supplementary Table 1. Infection efficiency of $\mathrm{HBV}$ genotype A2/B5/C2/D3 in three different hepatocyte cell culture-based systems.

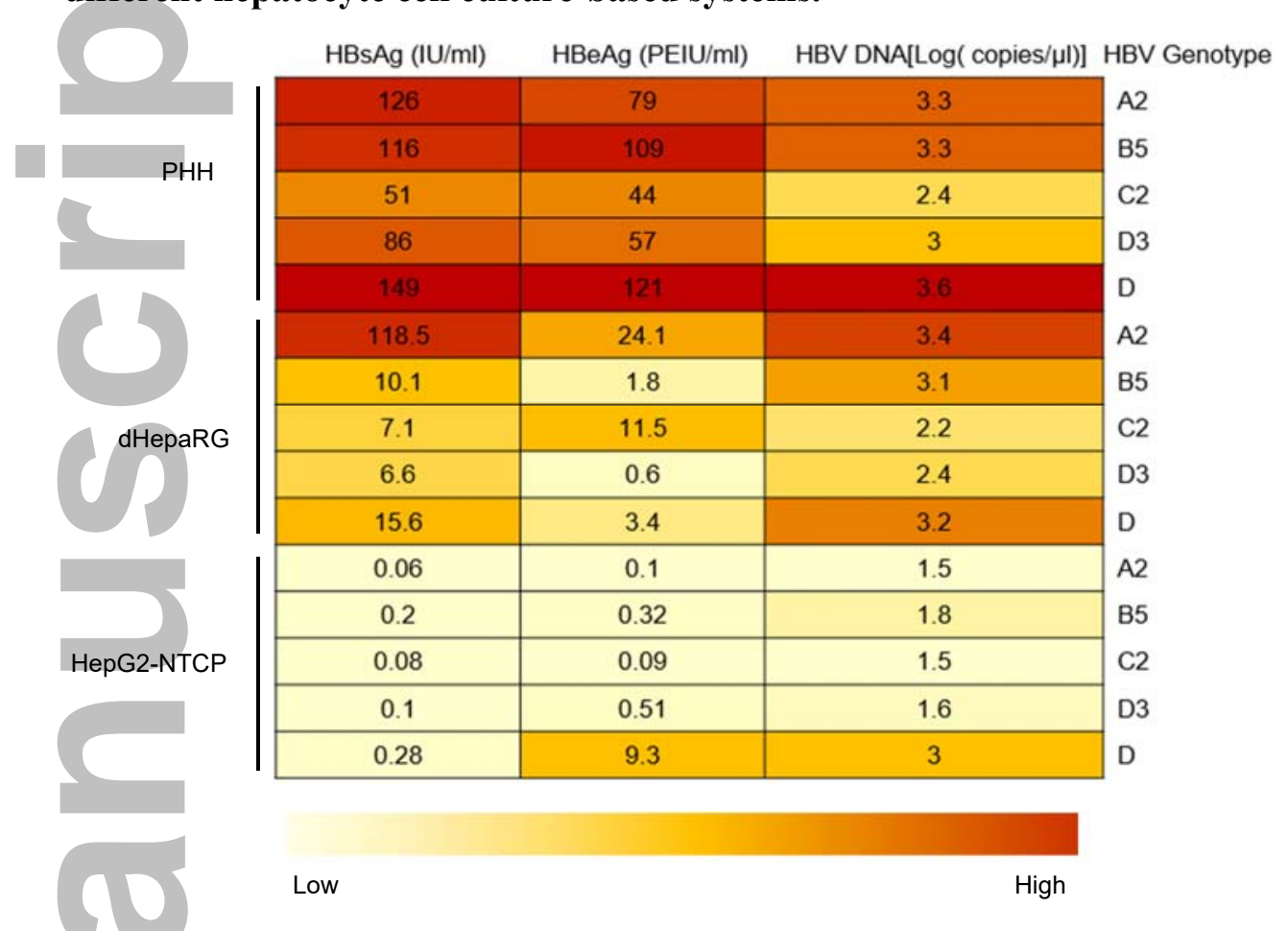

HBsAg, HBeAg and HBV DNA levels in culture medium at day 12 post infection (PHH and dHepaRG cells), or day 16 post infection (HepG2-NTCP cells) were shown with mean values, and expression levels were highlighted with different colors.

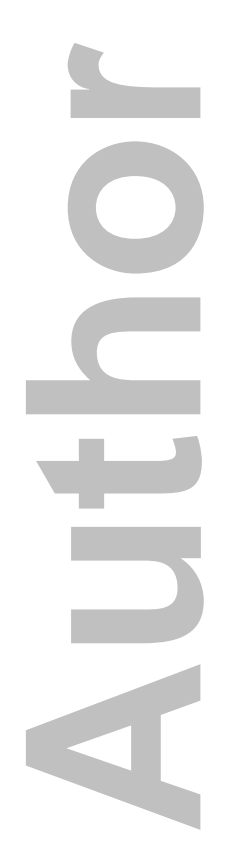


Supplementary Table 2. Information of primary antibodies used in this study.

Supplementary Table 2. Information of primary antibodies used in this study.
\begin{tabular}{|c|c|c|}
\hline Antibody & Vendor & Catalog No. \\
\hline HBsAg & Leica Biosystems & NCL-HBsAg-2 \\
\hline STAT1 & Cell Signaling Technology & $9172 \mathrm{~s}$ \\
\hline pSTAT1 & Cell Signaling Technology & $9167 \mathrm{~S}$ \\
\hline STAT2 & Santa Cruz Biotechnology & sc-476 \\
\hline pSTAT2 & Santa Cruz Biotechnology & sc-21689-R \\
\hline JAK1 & Cell Signaling Technology & $3344 \mathrm{~S}$ \\
\hline TYK2 & Cell Signaling Technology & $14193 \mathrm{~S}$ \\
\hline IFNAR1 & Santa Cruz Biotechnology & sc-7391 \\
\hline IFNAR2 & Santa Cruz Biotechnology & sc-376273 \\
\hline IRF9 & Santa Cruz Biotechnology & sc-365893 \\
\hline MDA5 & Cell Signaling Technology & 5321 \\
\hline RIG-I & Cell Signaling Technology & 3743 \\
\hline$\beta$-actin & Sigma & A3854 \\
\hline
\end{tabular}


Supplementary Table 3. Sequences of primers and probe used in this study.

\begin{tabular}{|c|c|}
\hline Primer Name & Sequences \\
\hline HBV DNA s & 5'-GCTGGATGTGTCTGCGGC-3“ \\
\hline HBV DNA as & 5'-GAGGACAAACGGGCAACATAC-3' \\
\hline HBV DNA probe & 5'-TAMRA-CATCCTGCTGCTATGCCTCATCTTCTTG-BHQ-3' \\
\hline HBV cccDNA s & 5'-ACCTCTCTTTACGCGGACTCC-3' \\
\hline HBV cccDNA as & 5'-CCCACCCAGGTAGCTAGAGTCA-3' \\
\hline HBV cccDNA probe & 5'-TAMRA+ATTGGTCTGCGCACCAGCACCA+ BHQ-3' \\
\hline HBV pgRNA s & 5'-GCCTTAGAGTCTCCTGAGCA-3' \\
\hline HBV pgRNA as & 5'-GAGGGAGTTCTTCTTCTAGG-3' \\
\hline OAS1 s & 5'-AAGGCTGGAATTTCATTCTC-3' \\
\hline OAS1 as & 5'-CATTTTCAGGTGGGACTCT-3' \\
\hline IFITM1 s & 5'-TCTTCTTGAACTGGTGCTGTC-3' \\
\hline IFITM1 as & 5'-GTCGCGAACCATCTTCCTGT-3' \\
\hline APOBEC3G s & 5'-CCGAGGACCCGAAGGTTAC-3' \\
\hline APOBEC $3 \mathrm{G}$ as & 5'-TCCAACAGTGCTGAAATTCG-3' \\
\hline ISG20 s & 5'-TCTACGACACGTCCACTGACA-3' \\
\hline ISG20 as & 5'-CTGTTCTGGATGCTCTTGTGC-3' \\
\hline CXCL10 s & 5'-AGGAACCTCCAGTCTCAGCA-3' \\
\hline CXCL10 as & 5'-ATTTTGCTCCCCTCTGGTTT-3' \\
\hline GBP5 s & 5'-ACATTAGTTCTGCTTGACACCG-3' \\
\hline GBP5 as & 5'-GCTGCTCAGTAAGAGTGCCAG-3' \\
\hline TNFSF13B s & 5'-CCTCACGGTGGTGTCTTTCTA-3' \\
\hline TNFSF13B as & 5'-AACGGCACGCTTATTTCTGCT-3' \\
\hline APOBEC3A s & 5'-GAGAAGGGACAAGCACATGG-3' \\
\hline APOBEC3A as & 5'-TGGATCCATCAAGTGTCTGG-3' \\
\hline SAMHD1 s & 5'-CCTCTCCTCGTCCGAATCATT-3' \\
\hline SAMHD1 as & 5'-CCACCCCTAGACTATGCTCAA-3' \\
\hline GBP1s & 5'-GTGGAACGTGTGAAAGCTGA-3' \\
\hline GBP1 as & 5'-CAACTGGACCCTGTCGTTCT--3' \\
\hline WARS s & 5'-TGACGGATGACGAGAAGTATCT-3' \\
\hline WARS as & 5'-GCCGAAAATGCCTTTCACTTG-3' \\
\hline TAP-1 s & 5'-CGCCTCACTGACTGGATTCTA-3' \\
\hline TAP-1 as & 5'-TCTGTTGGAAAAACTCCGTCTC-3' \\
\hline IRF1 s & 5'-CTGTGCGAGTGTACCGGATG-3' \\
\hline IRF1 as & 5'-ATCCCCACATGACTTCCTCTT-3' \\
\hline GAPDH s & 5'-GGTATCGTGGAAGGACTCATGA-3' \\
\hline GAPDH as & 5'-ATGCCAGTGAGCTTCCCGTTCAGC-3' \\
\hline
\end{tabular}




\section{References:}

[1] Wu M, Xu Y, Lin S, Zhang X, Xiang L, Yuan Z. Hepatitis B virus polymerase inhibits the interferon-inducible MyD88 promoter by blocking nuclear translocation of Stat1. J Gen Virol. 2007

[2] Sells MA, Chen ML, Acs G. Production of hepatitis B virus particles in Hep G2 cells transfected with cloned hepatitis B virus DNA. Proc Natl Acad Sci.1987

[3] Congrong Niu, Christine M. Livingston, Li Li, et al. The Smc5/6 Complex Restricts HBV when Localized to ND10 without Inducing an Innate Immune Response and Is Counteracted by the HBV X Protein Shortly after Infection. Plos one. 2017

[4] Lucifora J, Durantel D, Testoni B, et al. Control of hepatitis B virus replication by innate response of HepaRG cells. Hepatology. 2010

[5] Huan Yan, Guocai Zhong, Guangwei Xu, et al. Sodium taurocholate cotransporting polypeptide is a functional receptor for human hepatitis B and D virus. eLife. 2012

[6] Jansen, L., et al. An intrahepatic transcriptional signature of enhanced immune activity predicts response to peginterferon in chronic hepatitis B. Liver Int, 35(7): 1824-1832 (2015).

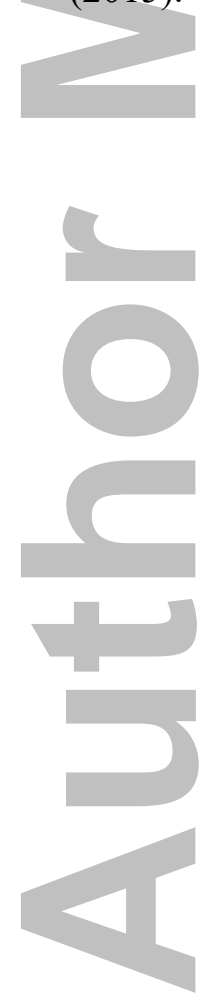



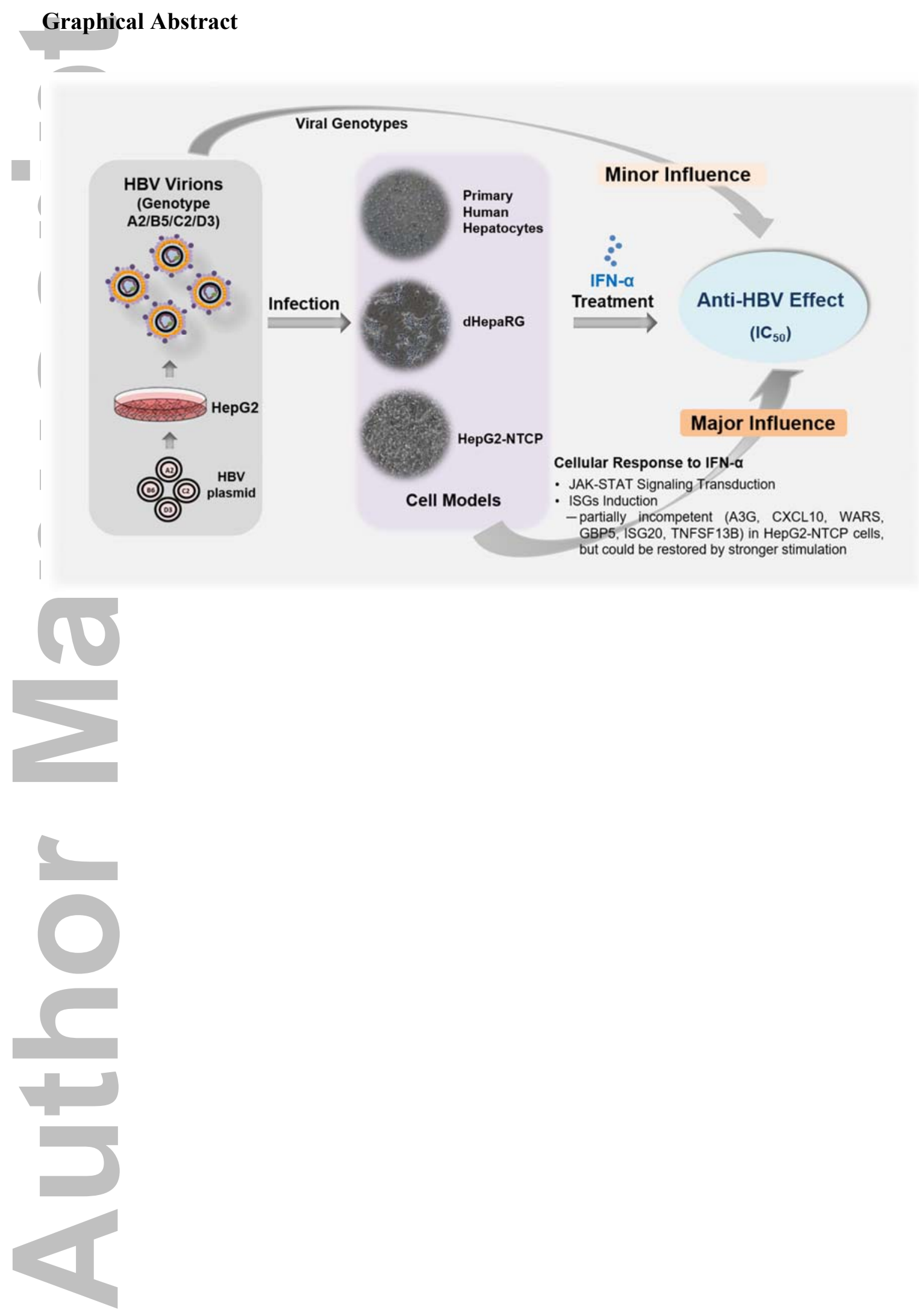


\section{University Library}

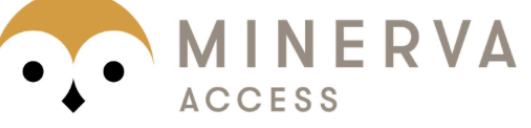

A gateway to Melbourne's research publications

Minerva Access is the Institutional Repository of The University of Melbourne

Author/s:

Shen, F;Li, Y;Wang, Y;Sozzi, V;Revill, PA;Liu, J;Gao, L;Yang, G;Lu, M;Sutter, K;Dittmer, U;Chen, J;Yuan, Z

Title:

Hepatitis B virus sensitivity to interferon- in hepatocytes is more associated with cellular interferon response than with viral genotype

Date:

2018-04-01

Citation:

Shen, F., Li, Y., Wang, Y., Sozzi, V., Revill, P. A., Liu, J., Gao, L., Yang, G., Lu, M., Sutter, K., Dittmer, U., Chen, J. \& Yuan, Z. (2018). Hepatitis B virus sensitivity to interferon- in hepatocytes is more associated with cellular interferon response than with viral genotype. HEPATOLOGY, 67 (4), pp.1237-1252. https://doi.org/10.1002/hep.29609.

Persistent Link:

http://hdl.handle.net/11343/283725 